\title{
Reduction of Breakdown Pressure by Filter Cake Removal Using Thermochemical Fluids and Solvents: Experimental and Numerical Studies
}

\author{
Zeeshan Tariq ${ }^{1}$, Murtada Saleh Aljawad ${ }^{1, *}{ }^{\mathbb{D}}$, Mohamed Mahmoud ${ }^{1, *}$, Olalekan Alade ${ }^{1}{ }^{1}$, \\ Muhammad Shahzad Kamal ${ }^{1}$ (D) and Ayman Al-Nakhli ${ }^{2}$ (I)
}

1 Department of Petroleum Engineering, King Fahd University of Petroleum \& Minerals, Dhahran 31261, Saudi Arabia; g201406240@kfupm.edu.sa (Z.T.); olalekan.alade@kfupm.edu.sa (O.A.); shahzadmalik@kfupm.edu.sa (M.S.K.)

2 Saudi Aramco, Dhahran 31261, Saudi Arabia; ayman.nakhli@aramco.com

* Correspondence: mjawad@kfupm.edu.sa (M.S.A.); mmahmoud@kfupm.edu.sa (M.M.)

Citation: Tariq, Z.; Aljawad, M.S.; Mahmoud, M.; Alade, O.; Kamal, M.S.; Al-Nakhli, A. Reduction of Breakdown Pressure by Filter Cake Removal Using Thermochemical Fluids and Solvents: Experimental and Numerical Studies. Molecules 2021, 26, 4407. https://doi.org/ $10.3390 /$ molecules 26154407

Academic Editors: Juan

Carlos Serrano-Ruiz and

Andrei Rotaru

Received: 26 June 2021

Accepted: 19 July 2021

Published: 21 July 2021

Publisher's Note: MDPI stays neutral with regard to jurisdictional claims in published maps and institutional affiliations.

Copyright: (c) 2021 by the authors. Licensee MDPI, Basel, Switzerland. This article is an open access article distributed under the terms and conditions of the Creative Commons Attribution (CC BY) license (https:/ / creativecommons.org/licenses/by/ $4.0 /)$.
Abstract: The process of well cleanup involves the removal of an impermeable layer of filter cake from the face of the formation. The inefficient removal of the filter cake imposes difficulty on fracturing operations. Filter cake's impermeable features increase the required pressure to fracture the formation. In this study, a novel method is introduced to reduce the required breakdown pressure to fracture the formation containing the water-based drilling fluid filter cake. The breakdown pressure was tested for five samples of similar properties using different solutions. A simulated borehole was drilled in the core samples. An impermeable filter cake using barite-weighted drilling fluid was built on the face of the drilled hole of each sample. The breakdown pressure for the virgin sample without damage (filter cake) was 6.9 MPa. The breakdown pressure increased to $26.7 \mathrm{MPa}$ after the formation of an impermeable filter cake. Partial removal of filter cake by chelating agent reduced the breakdown pressure to $17.9 \mathrm{MPa}$. Complete dissolution of the filter cake with chelating agents resulted in the breakdown pressure approximately equivalent to the virgin rock breakdown pressure, i.e., 6.8 MPa. The combined thermochemical and chelating agent solution removed the filter cake and reduced the breakdown pressure to $3.8 \mathrm{MPa}$. Post-treatment analysis was carried out using nuclear magnetic resonance (NMR) and scratch test. NMR showed the pore size redistributions with good communication between different pores after the thermochemical removal of filter cake. At the same time, there was no communication between the different pores due to permeability impairment after filter cake formation. The diffusion coupling through NMR scans confirmed the higher interconnectivity between different pores systems after the combined thermochemical and chelating agent treatment. Compressive strength was measured from the scratch test, confirming that filter cake formation caused added strength to the rock that impacts the rock breakdown pressure. The average compressive strength of the original specimen was $44.5 \mathrm{MPa}$ that increased to $73.5 \mathrm{MPa}$ after the formation of filter cake. When the filter cake was partially removed, the strength was reduced to $61.7 \mathrm{MPa}$. Complete removal with chelating agents removed the extra strength that was added due to the filter cake presence. Thermochemical and chelating agents resulted in a significantly lower compressive strength of 25.3 MPa. A numerical model was created to observe the reduction in breakdown pressure due to the thermochemical treatment of the filter cake. The result presented in this study showed the engineering applications of thermochemical treatment for filter cake removal.

Keywords: filter cake formation; filter cake removal; breakdown pressure; thermochemical; modeling

\section{Introduction}

In an overbalanced drilling operation, the filter cake is formed on the wellbore wall due to the difference in hydrostatic pressure between the drilling fluids and the reservoir fluid. This filter cake creates a very thin impermeable layer. From the drilling perspective, 
this layer is very useful as it mitigates the loss circulation of drilling fluids in the permeable geological formation, but from production and reservoir perspectives, if this thin layer is not removed, then it can restrict the flow and causes an additional pressure drop that ultimately can reduce the productivity of the well [1-3]. The additional pressure drop due to the invasion of the drilling fluid into the reservoir formation is termed skin. In addition to the skin damage, the drilling fluids are not compatible with the reservoir rocks and fluids. They could cause the swelling of clays, emulsions, wettability alteration of the formation near the wellbore, and scale formations. Therefore, during well completion, the first step taken is to remove this impermeable layer. The removal of the filter cake is challenging, exhaustive, costly, and time consuming. This expensive task becomes more challenging in the long horizontal wells because of the longer contact time of the drilling fluids with the reservoir sections. The impermeable filter cake layer imposes an additional resistance to fracturing, especially in extended reach horizontal wells. This layer adds more strength to the wellbore and will increase the breakdown pressure required to break the reservoir in tight formation as well as in permeable formations.

Breakdown pressure is the pressure required to create the fracture in the reservoir and allows the fracturing fluid to penetrate in the given formation [4-8]. Fractures are created by injecting a pressurized fluid that provides conductive paths between the formation matrix, natural fractures, and the wellbore $[9,10]$. Water-based fluid, which most times contain around $99.5 \%$ of water-sand mixture with $0.5 \%$ additives, forms the slurry that is injected to propagate the fracture after an initial volume of pad fluids are injected to initiate the fracture [11-13]. Based on the type of formation and its characteristics, multiple mixtures of fracturing fluids can improve the fracturing process's effectiveness. Typical fracturing fluids used to fracture unconventional reservoirs are oil, water, polymers, linear gel, methanol, or a combination of water and methanol [14,15].

When drilling a horizontal well, the drilling fluid will have more contact and residency in the wellbore than in the vertical well because of the length of the horizontal section. This will impose more damage due to the formation of the filter cake at the face of the formation. The drilling fluid solids will invade the formation and create a positive skin in the near-wellbore area in addition to the impermeable filter cake [16-19]. Water-based drilling fluids are the common type of drilling fluids used to drill different well types due to their low environmental impact compared to oil-based drilling fluids. In some cases, in which the formation rock is very sensitive to water, oil-based drilling fluids prevent the formation damage and wellbore stability issues. Different types of oil-based drilling fluids are used to drill sensitive formations, such as invert-emulsion drilling fluid [20]. The filter cake removal in oil-based drilling fluids is different than that in the case of water-based because of the difference in the composition of the filter cake. Table 1 summarizes some of the scenarios for filter cake removal.

Table 1. Different types of filter cake removal scenarios in oil- and water-based drilling fluids.

\begin{tabular}{|c|c|c|c|}
\hline Filter Cake Type & Filter Cake Remover & Comments & References \\
\hline \multirow{3}{*}{ Barite water-based mud } & DTPA chelating agent $+\mathrm{K}_{2} \mathrm{CO}_{3}+$ Enzyme & Removal efficiency reached $90 \%$ at $270{ }^{\circ} \mathrm{F}$ & [21] \\
\hline & EDTA chelating agent $+\mathrm{K}_{2} \mathrm{CO}_{3}+$ Enzyme & Removal efficiency reached $85 \%$ at $270{ }^{\circ} \mathrm{F}$ & [22] \\
\hline & EDTA chelating + thermochemical & $\begin{array}{l}\text { Removal efficiency reached more than } 80 \% \text { at } \\
\text { different temperatures }\end{array}$ & [23] \\
\hline \multirow{2}{*}{ Barite Oil-based mud } & $\begin{array}{c}\text { Multi-stage } \\
\left(\text { Solvent }+ \text { GLDA }+\mathrm{K}_{2} \mathrm{CO}_{3}+\mathrm{HCl}\right)\end{array}$ & $\begin{array}{l}\text { Removal efficiency reached } 83 \% \text { at different } \\
\text { temperatures }\end{array}$ & [24] \\
\hline & EDTA chelating agent $+\mathrm{K}_{2} \mathrm{CO}_{3}+$ EGMBE & $\begin{array}{l}\text { Removal efficiency reached } 80 \% \text { at different } \\
\text { temperatures }\end{array}$ & [24] \\
\hline
\end{tabular}


Table 1. Cont.

\begin{tabular}{|c|c|c|c|}
\hline Filter Cake Type & Filter Cake Remover & Comments & References \\
\hline $\begin{array}{c}\text { Calcium carbonate } \\
\text { water-based, drill in fluid }\end{array}$ & Acid precursor of organic acids & Filter cake removed efficiently & {$[25]$} \\
\hline Barite filter cake & Formate brines & Barite solubility reached $3500 \mathrm{mg} / \mathrm{L}$ at $100^{\circ} \mathrm{C}$ & [26] \\
\hline Invert emulsion filter cake & Oil wetting agents, a precursor of organic acid & Uniform removal of filter cake & {$[27,28]$} \\
\hline Invert emulsion filter cake & Microemulsion & $\begin{array}{l}\text { Filter cake removal efficiency reached } 97 \% \\
\text { after } 24 \mathrm{~h}\end{array}$ & {$[29]$} \\
\hline Invert emulsion filter cake & Microemulsion & Efficient removal of the oil-based filter cake & {$[30,31]$} \\
\hline $\begin{array}{l}\text { Synthetic and oil-based } \\
\text { drilling filter cake }\end{array}$ & Microemulsion + surfactants/co-surfactants & Efficient removal of the oil-based filter cake & [32] \\
\hline
\end{tabular}

Barite is a commonly used weighting material in oil- and water-based drilling fluids to drill deep in oil and gas reservoirs. Barite has very low solubility in mineral and organic acids, compared to other weighting materials in drilling fluids. Barite also has moderate solubility in high pH chelating agents such as EDTA and DTPA [23]. The filter cake can be removed through either a single-stage or multi-stage process based on the computability of the remover fluid ingredients [23]. This study aims to investigate the removal of barite filter cake and its impact on the breakdown pressure of different rocks. In this work, thermochemical fluids (TCF) were used after simulated drilling operations to remove the barite-based filter cake completely. The new method can remove the barite-based filter cake and create microfractures and tiny cracks that can increase wells' productivity and are instrumental in wells' flowback period. This can expedite the operation of well cleanup.

\section{Materials and Methods}

\subsection{Drilling Fluid Formulation}

In this study, the typical field formulations were used to form the filter cake for the water-based drilling fluids. In water-based drilling fluid, 0.691 barrels (bbls) of the water was used. The drilling fluids additives were comprised of barite, sodium chloride $(\mathrm{NaCl})$, potassium chloride $(\mathrm{KCl})$, calcium carbonate $\left(\mathrm{CaCO}_{3}\right)$, bentonite, Xanthan Gum (XC) polymer, and potassium hydroxide $(\mathrm{KOH})$. The amount of drilling fluid additives was: barite was 352 lbs, $\mathrm{NaCl} 66$ lbs, $\mathrm{KCl} 20$ lbs, $\mathrm{CaCO}_{3} 5.0$ lbs, bentonite 4.0 lbs, XC polymer $0.5 \mathrm{lbs}$, and $\mathrm{KOH} 0.5 \mathrm{lbs}$.

\subsection{Core Preparation}

Different cement cubicle blocks with a cement and sand ratio of 1:1 were prepared. The blocks were $101.6 \mathrm{~mm}$ long and $101.6 \mathrm{~mm}$ wide. The cylindrical core samples were taken out from the blocks. The dimensions of the cylindrical core samples were $50.8 \mathrm{~mm}$ in diameter and $50.8 \mathrm{~mm}$ in length. A synthetic borehole was created at the center of each specimen, which represents the wellbore with the dimension of $6 \mathrm{~mm}$ diameter and $19 \mathrm{~mm}$ depth. The cement samples were cast according to guidelines given in previous publications [33-38]. The illustration of sample preparation is given in Figure 1. The petrophysical and mechanical properties of cement samples are described in Table 2.

\subsection{Thermochemical Fluids}

To treat the water-based drilling fluid filter cake, thermochemical fluids were utilized. The thermochemical used in this study consisted of salts of nitrogen such as ammonium chloride $\left(\mathrm{NH}_{4} \mathrm{Cl}\right)$ and sodium nitrite $\left(\mathrm{NaNO}_{2}\right)$. The reaction between $\mathrm{NH}_{4} \mathrm{Cl}$ and $\mathrm{NaNO}_{2}$ is irreversible and highly exothermic that resulted in the in situ generations of nitrogen gas [39]. This reaction is normally considered a green reaction because it is mainly composed of salts $[40,41]$. Due to the high-pressure temperature generation, thermochemical fluids were successfully used in the oil and gas industry for several purposes such as wax removal [42], heavy oil production [43], breakdown pressure reduction [44-46], increasing stimulated reservoir volume [47], and enhanced oil recovery (EOR) applications [48]. Mahmoud [23] used thermochemical fluids along with chelating agents to remove the 
filter cake formed by barite-weighted drilling fluids in oil- and water-based types. He reported a removal efficiency of $80 \%$ and more in different cases. Ba Alawi et al. [49] used thermochemical fluids combined with hydrochloric acid to stimulate heterogeneous carbonate formations through the acid diversion mechanism that was enforced by TCF. They showed that TCF combined with $\mathrm{HCl}$ can stimulate large contrast in permeability. They conducted parallel core flooding experiments using high and low permeability carbonate rocks, and both rocks were stimulated efficiently due to the presence of TCF. Aljawad et al. [50] showed that TCF could generate very high pressure and temperature through fractured reservoirs. They showed that TCF could be combined with hydraulic fracture treatments to create a complex fracture network to enhance the well productivity.
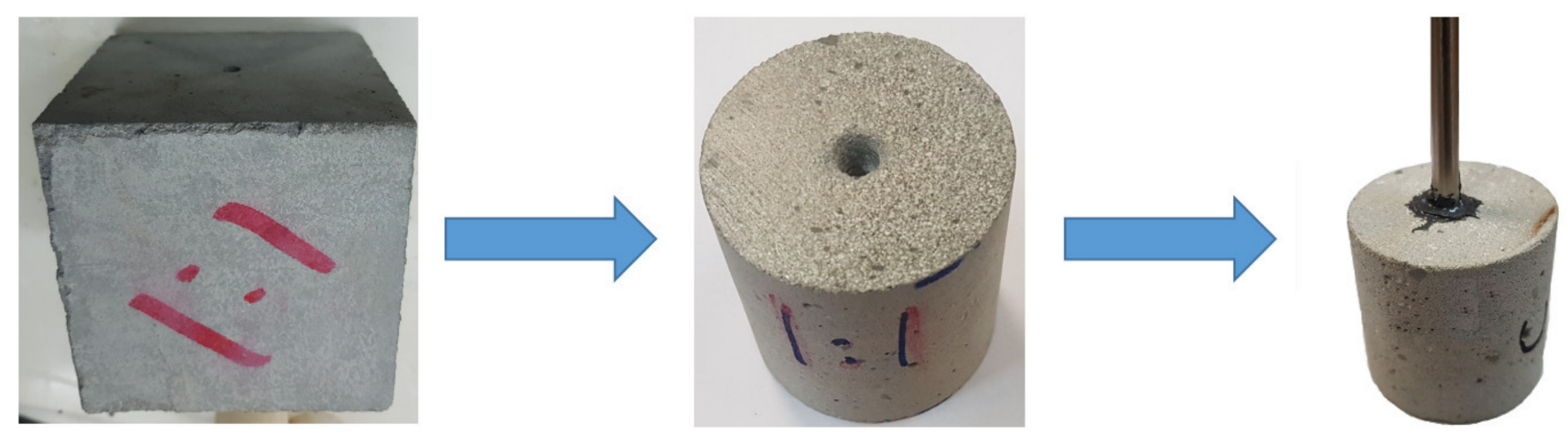

Figure 1. Illustration of the sample preparation.

Table 2. Petrophysical and rock mechanical properties of the tested samples.

\begin{tabular}{ccc}
\hline Rock Parameters & Values & Units \\
\hline Permeability & 0.5 & $\mathrm{mD}$ \\
Porosity & 17 & $\%$ \\
Unconfined Compressive Strength & 41.3 & $\mathrm{MPa}$ \\
Tensile Strength & 8.9 & $\mathrm{MPa}$ \\
Compressional Wave Velocity & 3050 & $\mathrm{~m} / \mathrm{s}$ \\
Shear Wave Velocity & 1900 & $\mathrm{~m} / \mathrm{s}$ \\
Dynamic Poisson's Ratio & 0.27 & - \\
Dynamic Young's Modulus & 34 & $\mathrm{GPa}$ \\
Bulk Density & 2.7 & $\mathrm{~g} / \mathrm{cc}$ \\
\hline
\end{tabular}

The thermochemical reaction between $\mathrm{NH}_{4} \mathrm{Cl}$ and $\mathrm{NaNO}_{2}$ can be given by Equation (1) as follows:

$$
\mathrm{NH}_{4} \mathrm{Cl}+\mathrm{NaNO}_{2} \rightarrow\left[\begin{array}{c}
\mathrm{NH}_{4} \mathrm{NO}_{2}+\mathrm{NaCl}_{\text {Th }} \mathrm{NH}_{4} \mathrm{NO}_{2} \\
\text { Themolabile }
\end{array}\right] \rightarrow \mathrm{NaCl}+2 \mathrm{H}_{2} \mathrm{O}+\mathrm{N}_{2} \text { (gas) }+\Delta \mathrm{H} \text { (heat) }
$$

The reaction kinetics of the thermochemical fluids that were utilized in this study to remove the drilling fluid-based filter cake was extensively investigated, and the necessary reaction parameters such as specific heat capacity $(C)$, enthalpy change $(\Delta \mathrm{H})$, and thermal conductivities $(\lambda)$ were determined. These reaction parameters are reported in Table 3. 
Table 3. Kinetics of thermochemical fluids.

\begin{tabular}{cc}
\hline Reaction Parameters & Values \\
\hline$C\left(\frac{\mathrm{J}}{\mathrm{mol} . \mathrm{K}}\right)$ & $85-110$ \\
\hline$\lambda\left(\frac{\mathrm{W}}{\mathrm{m} \mathrm{K}}\right)$ & $0.1-0.6$ \\
\hline$\Delta \mathrm{H}\left(\frac{\mathrm{kJ}}{\mathrm{mol}}\right)$ & 369 \\
\hline
\end{tabular}

Thermochemical fluids resulted in the generation of enormously high pressure. Figure 2 shows the plot of pressure generated by the reaction of one molar and two molar concentrations of $\mathrm{NH}_{4} \mathrm{Cl}$ and $\mathrm{NaNO}_{2}$ in an insulated high pressure and high temperature microreactor. Two molar concentrations of thermochemical fluids could generate a pressure of $38 \mathrm{MPa}$ in $36 \mathrm{~s}$, while one molar concentration of thermochemical fluids could generate a pressure of $24.13 \mathrm{MPa}$ at the same time.

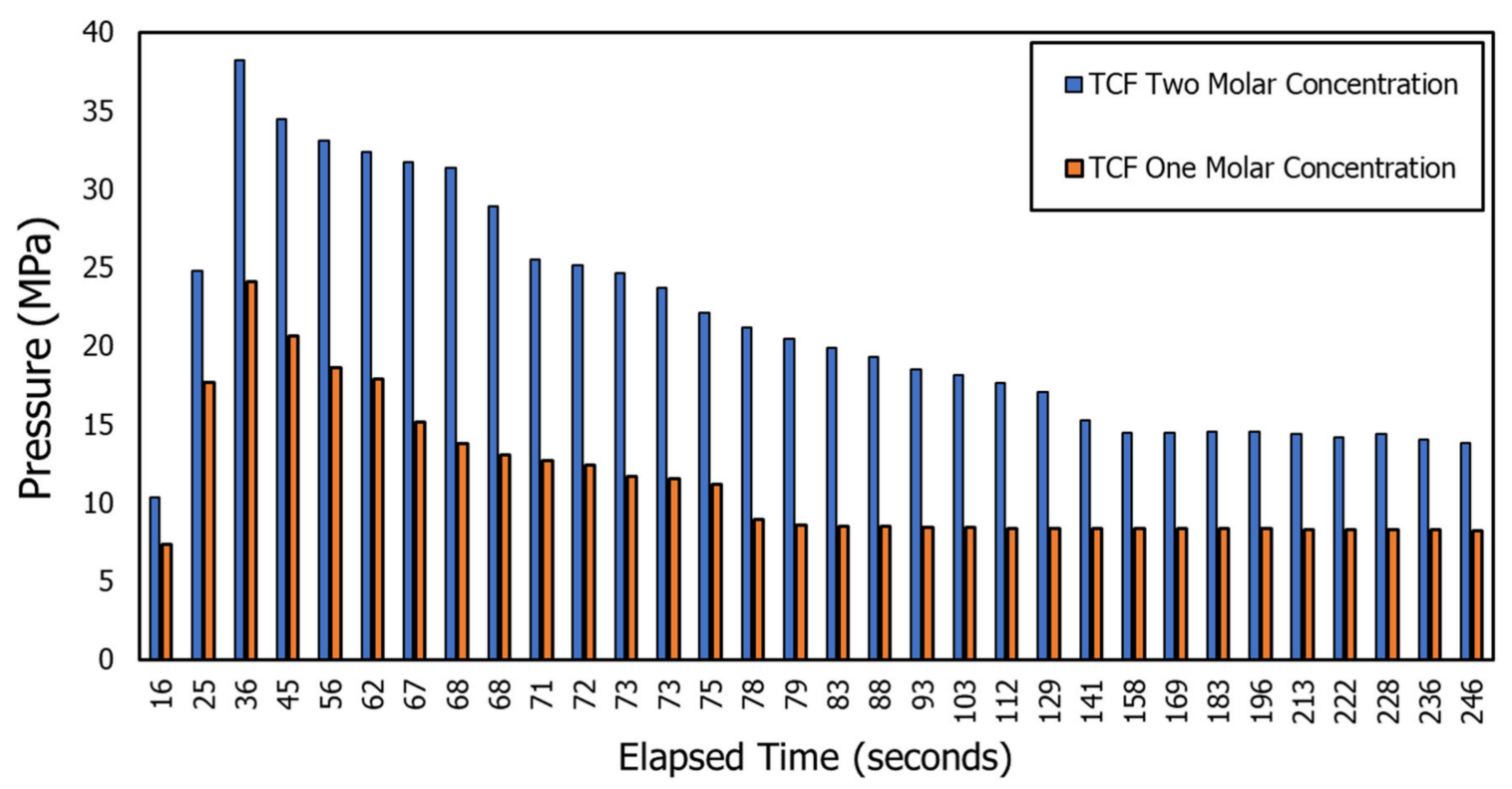

Figure 2. Effect of reactants molar concentration on pressure pulse generation due to thermochemical fluids.

\subsection{Chelating Agent}

In this study, diethylenetriaminepentaacetic acid (DTPA) and glutamic acid (GLDA) chelating agents were used, along with the TCFs to remove the filter cake. The role of the chelating agent is to react and make a stable product. DTPA can dissolve the rock minerals. Through core-flooding experiments, Barri et al. [51] found that DTPA can create wormholes in the carbonate reservoir rocks. Recently in our previous study [52], we found that chelating agents can improve the fracture conductivity by many folds because of the rock dissolution. Based on previous experiences, DTPA and GLDA were used to dissolve filter cake. The reaction between TCFs occurs when a high temperature is reached. The fluids are pumped at the surface temperature and gain heat as they approach the wellbore downhole. The reaction will occur near the damaged zone, which usually takes 30 to 60 min to start. The study suggests adding chelating agents such as DTPA to the TCFs, which is a noncorrosive agent.

\subsection{Experimental Setup}

The experimental setup comprised of a high-pressure injection pump, a $50.8 \mathrm{~mm}$ core holder, two-piston accumulators of volume one liter, a high-resolution data acquisition and 
monitoring system, high-pressure transducers, high-pressure valves, and high-pressure injection lines. Figure 3 shows the experimental process flow diagram used to form the filter cake. The same setup was used to dissolve/remove the filter cake and performing the hydraulic fracturing experiments.

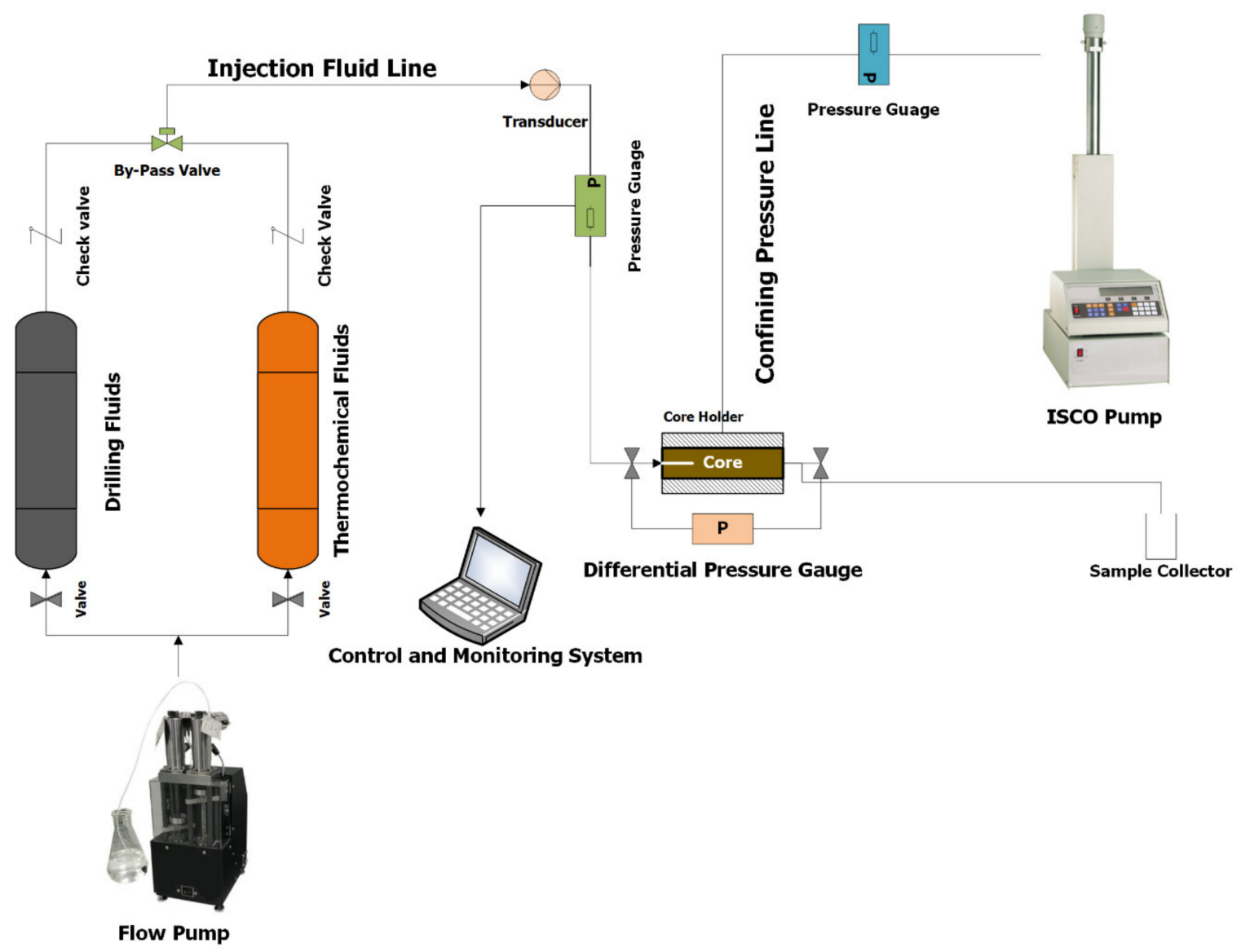

Figure 3. A schematic of filter cake and breakdown pressure setup.

The experimental study proceeded with the formation of the filter cake on the borehole wall of the samples, a typical example of the sample with a borehole is shown in Figure 1.

To create the filter cake, a drilling fluid was injected. To create and remove the filter cake, the breakdown pressure setup was used. The filter cake was created by applying a pressure difference of $200 \mathrm{psi}$ at an ambient temperature condition. The filter cake is impermeable, which means it has zero permeability. The impermeable nature of the filter cake was tested by applying a constant pressure of $100 \mathrm{psi}$ on the borehole of the cylindrical samples for $2 \mathrm{~h}$. The pressure did not decline and remained constant over $2 \mathrm{~h}$, confirming the presence of filter cake. After the generation of the filter cake, the same setup was used to remove the filter cake.

To remove the filter cake, an experimental plan was followed. Table 4 shows the experimental plan, the number of fracturing experiments, the type of fracturing fluids used to fracture the samples having the filter cake, and the type of characterization technique used after the fracturing experiment. A total of five fracturing experiments were conducted. Different chelating agents and thermochemical fluids were used. 
Table 4. Experimental methodology of the breakdown pressure.

\begin{tabular}{|c|c|c|c|c|c|}
\hline Experiments & Fracturing Fluid & $\begin{array}{l}\text { Filter Cake } \\
\text { Formation }\end{array}$ & NMR Scan & Scratch Test & Comment \\
\hline 1 & Water & No & Yes & Yes & Base case experiment without filter cake. \\
\hline 2 & Water & Yes & Yes & Yes & $\begin{array}{l}\text { Breakdown pressure experiment with water on } \\
\text { filter cake }\end{array}$ \\
\hline 3 & $20 w t \%$ DTPA & Yes & Yes & Yes & $\begin{array}{l}\text { Breakdown pressure experiment with DTPA } \\
\text { chelating agent only on filter cake }\end{array}$ \\
\hline 4 & $\begin{array}{c}20 w t \% \text { DTPA }+10 w t \% \text { GLDA + } \\
9 w t \% \mathrm{~K}_{2} \mathrm{CO}_{3}\end{array}$ & Yes & Yes & Yes & $\begin{array}{l}\text { Breakdown pressure experiment with mixed } \\
\text { chelating agent only on filter cake }\end{array}$ \\
\hline 5 & Thermochemical + DTPA & Yes & Yes & Yes & $\begin{array}{l}\text { Breakdown pressure experiment with chelating } \\
\text { agent and thermochemical fluids only on filter cake }\end{array}$ \\
\hline
\end{tabular}

Figure 4 shows the NMR core holder used to scan the rocks before and after fracturing. The Teflon cell can carry a pressure up to $500 \mathrm{psi}$, the rocks were saturated with $3 \mathrm{wt} \% \mathrm{KCl}$ brine at 1000 psi for $24 \mathrm{~h}$ before the NMR scans. A $2 \mathrm{MHz}$ NMR core analyzer was used.

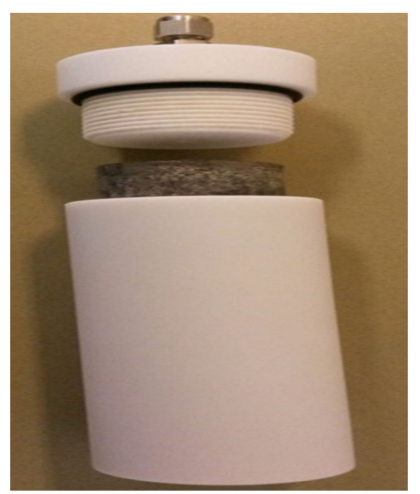

Figure 4. A schematic of the NMR core holder.

\section{Results and Discussions}

\subsection{Breakdown Pressure Results}

A total of five breakdown pressure experiments were carried out on five different samples with and without having filter cake. When there was no filter cake, the original rock breakdown pressure with water was $6.88 \mathrm{MPa}$. The filter cake increased the required breakdown pressure from $6.88 \mathrm{MPa}$ to $26.7 \mathrm{MPa}$. The $20 \mathrm{wt} \%$ DTPA chelating agent at $200{ }^{\circ} \mathrm{F}$ was used to partially remove the filter cake. Approximately, 45\% of the filter cake was removed when soaked for six hours in a DTPA solution. The pH of DTPA was maintained at 11. The partial removal of filter cake resulted in a breakdown pressure of 17.93 MPa. The fourth experiment was carried out with the combination of different chelating agents. A mixture of $20 \mathrm{wt} \%$ DTPA chelating agent, $10 \mathrm{wt} \%$ GLDA, and $9 \mathrm{wt} \% \mathrm{~K}_{2} \mathrm{CO}_{3}$ was used at $200{ }^{\circ} \mathrm{F}$ temperature to completely dissolve the filter cake. The overall $\mathrm{pH}$ of the solution was 11. After the complete removal of the filter cake, a breakdown pressure of $6.82 \mathrm{MPa}$ was observed. The fifth experiment was carried out with the combination of a chelating agent and thermochemical fluids. In this experiment, thermochemical fluids resulted in the generation of high pressure and high temperature. High pressure was generated due to the liberation of nitrogen gas, which resulted in the creation of micro and macro cracks in the sample. The high-temperature generation triggered the chelating agents. The combined effect of thermochemical fluids and chelating agents resulted in a significant reduction of the breakdown pressure to $3.78 \mathrm{MPa}$. Figure 5 shows the continuous injection pressure versus time curve for the different cases. The injection pressures were recorded till the rock fracture. The peak pressure corresponds to the breakdown pressure. Figure 6 shows the cross-sectional views of the different fractured samples. 


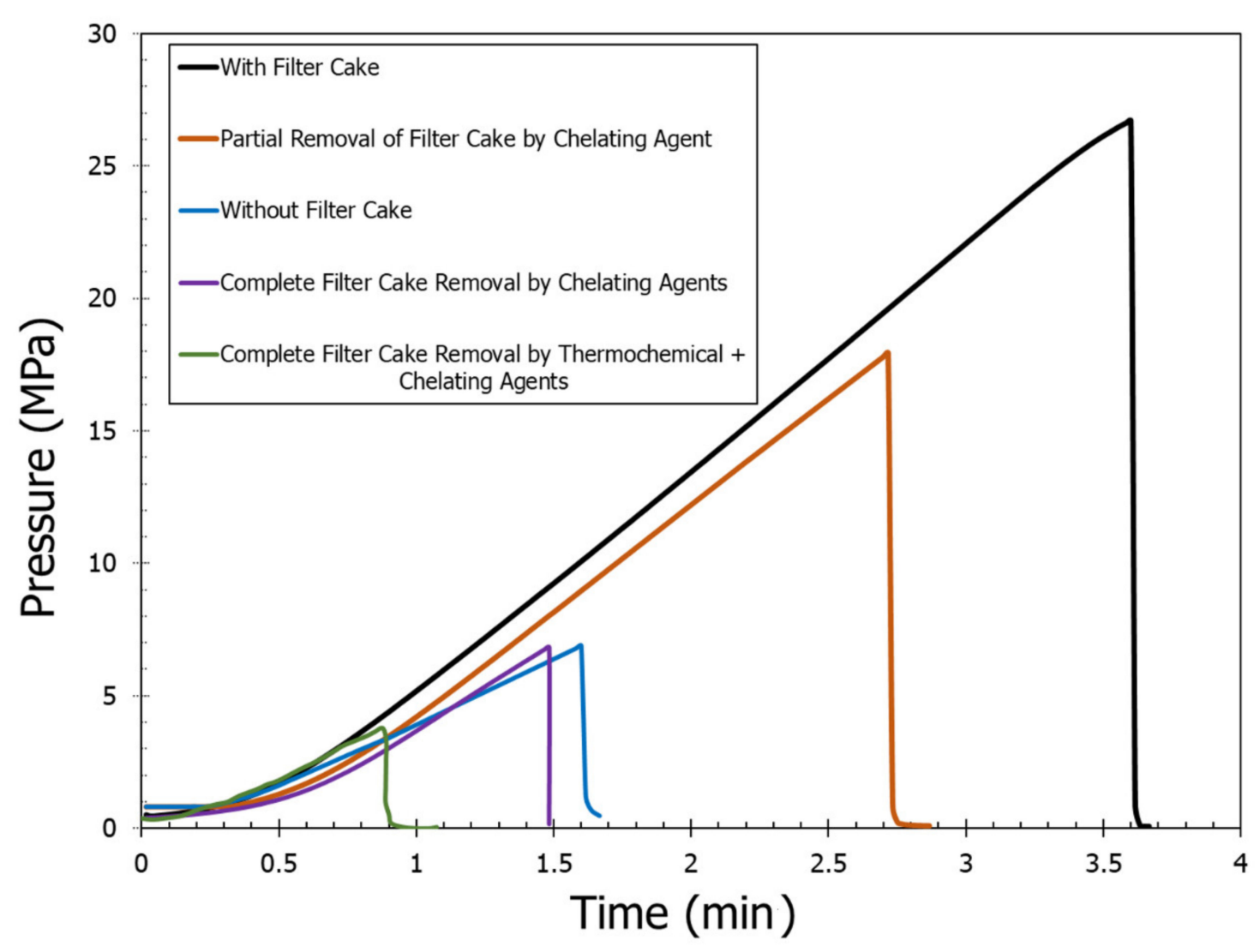

Figure 5. Pressure-time curves for different cases.

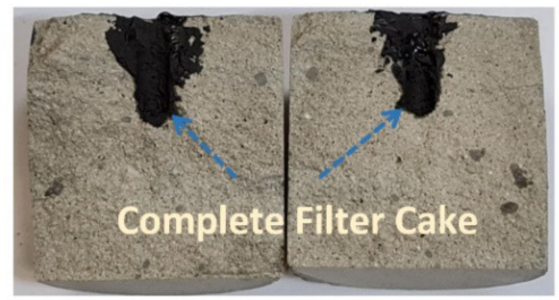

(a)

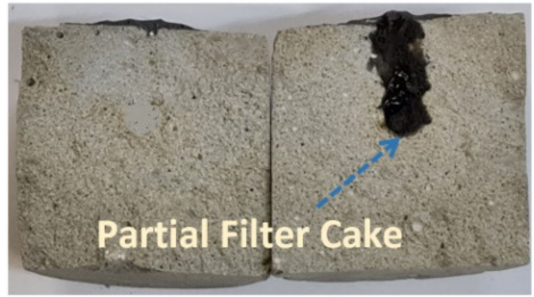

(b)

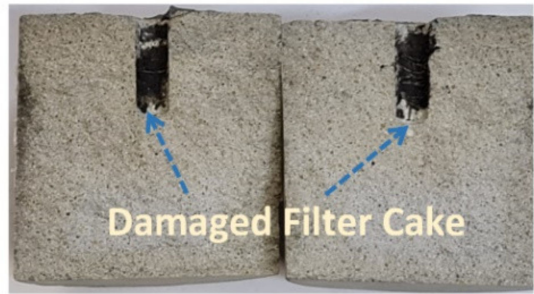

(c)

Figure 6. Cross-sectional views of the specimens treated with different fluids: (a) complete filter cake, (b) partial filter cake, and (c) damaged filter cake from combined thermochemical fluids and chelating agents.

The compressive strength of the treated samples was measured from the scratch test. Scratch test is an indirect way to measure the continuous compressive strength. The strength was measured by creating a groove along the length of the sample on the cross section, from the top ( $0 \mathrm{~mm}$ depth) to the bottom (19 $\mathrm{mm}$ depth) along the borehole. The average compressive strength of the sample without any filter cake was $44.5 \mathrm{MPa}$ that increased to $73.5 \mathrm{MPa}$ after the creation of the complete filter cake. When the filter cake was removed partially, the strength was reduced to $61.7 \mathrm{MPa}$. Complete removal with chelating agents removed the extra strength that was added due to the filter cake presence, resulting in $40.4 \mathrm{MPa}$. Filter cake removal with the combined thermochemical and chelating agents resulted in a significantly lower compressive strength of $25.3 \mathrm{MPa}$. Figure 7 shows the variation in the continuous compressive strength profiles of the fractured rock samples for five different cases. Scratch test results are aligned with the breakdown pressure and confirmed that the filter cake formation caused added strength to the rock that impacts the rock breakdown pressure. 


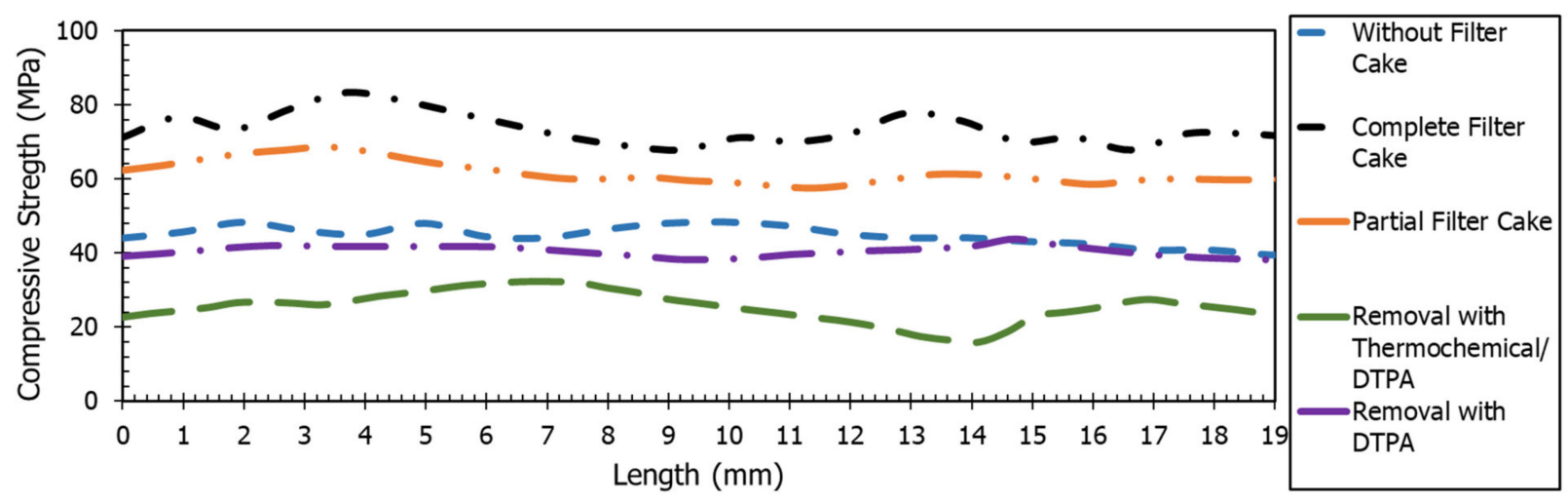

Figure 7. Continuous compressive strength profiles were recorded from the scratch test of the fractured rocks with different fracturing fluids. The strength measured on the cross section of the sample from top to the bottom along the borehole.

Figure 8 shows the cross-sectional view of the fractured $101.4 \mathrm{~mm}$ by $101.4 \mathrm{~mm}$ cubicle block. The picture was taken after the thermochemical reaction where the block was fractured. The microfractures were created as a result of the huge pressure generated from the thermochemical reaction. The thermochemical treatment for the filter cake created microfractures around the hole (wellbore), and these micro fractures reduced the required breakdown pressure compared to the native rock state.

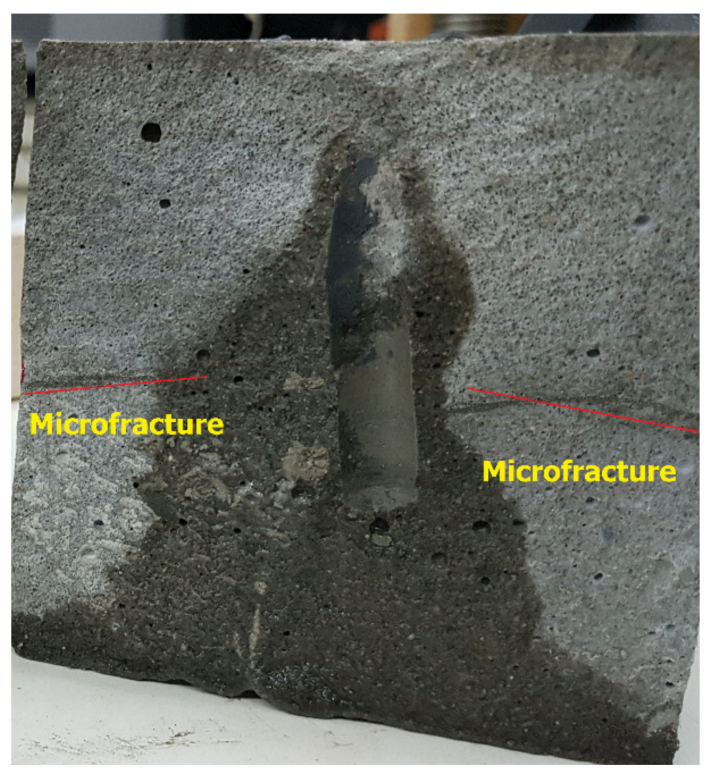

Figure 8. A cross-sectional view of the fractured sample showed the presence of microfractures (red line) due to the thermochemical treatment.

\subsection{NMR Results}

NMR scans were conducted for different cases by coring $38.1 \mathrm{~mm}$ diameter samples from the original cylindrical samples. Figure 9 shows the NMR scans for the rock sample without filter cake before and after fracturing with water. NMR showed that the rock sample has three pore systems that are well connected (through diffusion coupling). The largest pore system represents the drilled hole in the rock sample. After fracturing with water, NMR diffusion coupling showed a better connection between the micro- and mesopore system due to the creation of the fracture. The three peaks in the NMR scan represent micro-, meso-, and macropores in which the micro appears at relaxation time less than $2 \mathrm{msec}$ and the meso between 3 and $300 \mathrm{msec}$, and the macro appeared at relaxation time greater than $400 \mathrm{msec}$. 


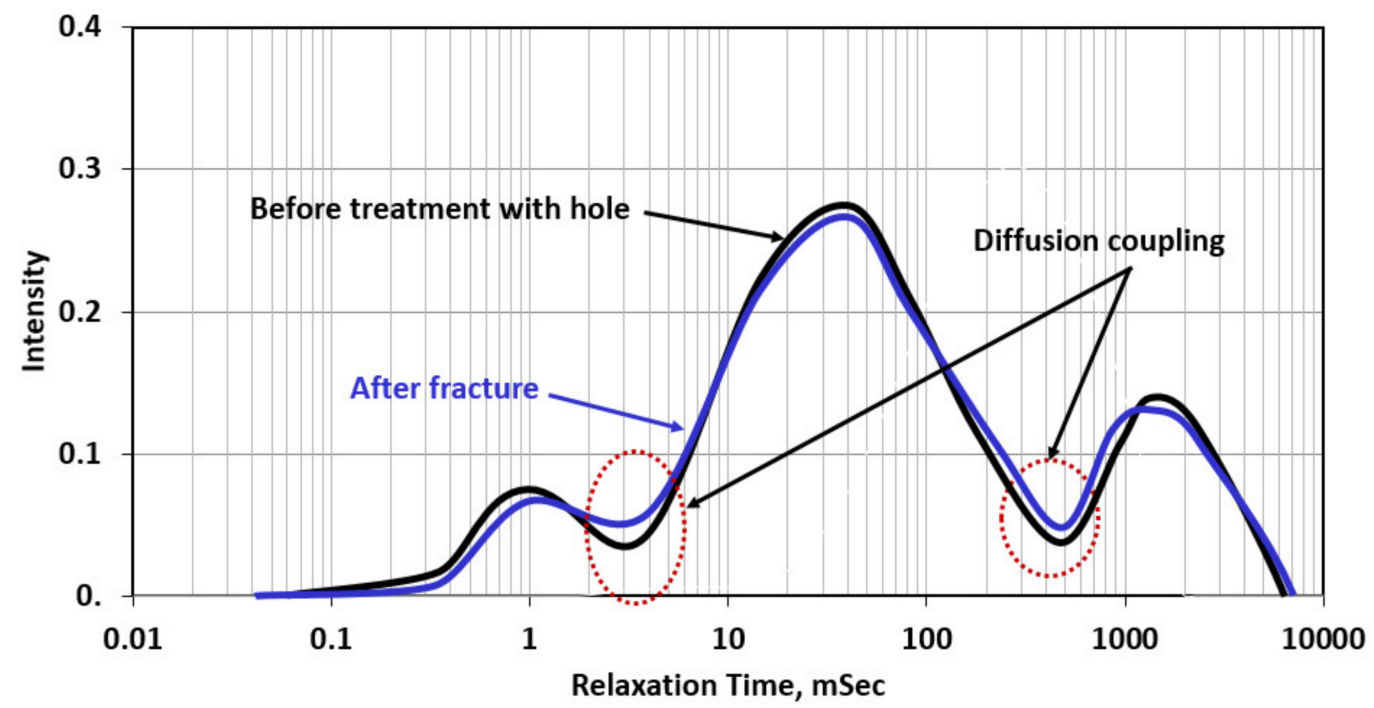

Figure 9. NMR scans for the rock samples without filter cake before and after fracturing (Experiment 1).

Figure 10 shows the NMR scans for the rock with the formed filter cake (barite weighed in water-based drilling fluid). The rock was scanned twice; the first one represents the rock with the filter cake (before treatment) in which the filter cake completely plugged the connections between the drilled hole and the rock, in addition to partial plugging for the connection between micro- and mesopores due to the invasion of the drilling fluid filtrate. After fracturing with water, in the presence of the filter cake, the created fracture enhanced the connectivity between the hole and the rock. Additionally, the connectivity between micro- and mesopores was enhanced due to the creation of the fracture. Compared to Figure 9, the filter cake reduced the diffusion coupling between different pore systems in the rocks and this is reflected by the decrease in the intensity of the diffusion coupling. Filter cake formation around the drilled hole reduced caused isolation between the hole and the rock, and as shown in Figure 10, there is complete isolation between the meso- and macropores system in which the intensity reached zero.

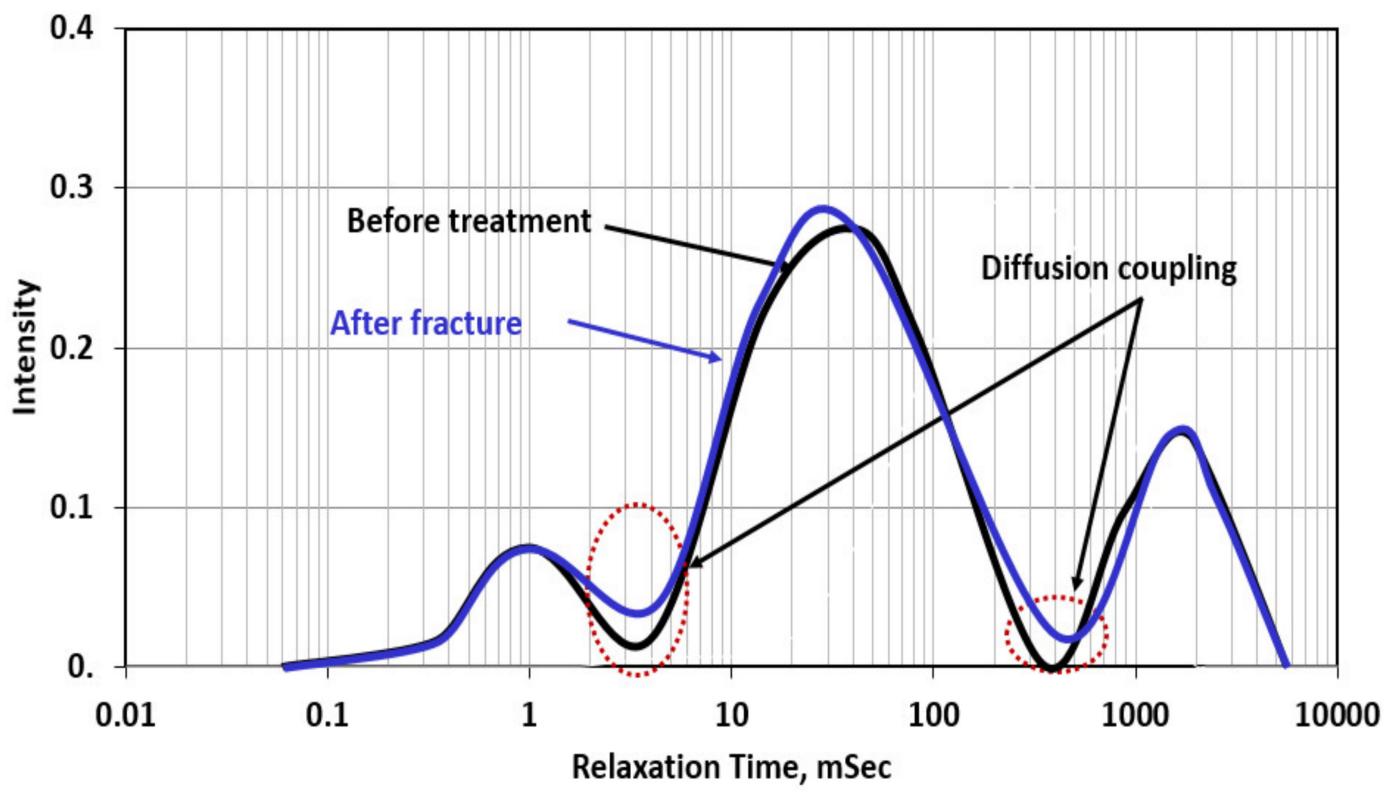

Figure 10. NMR scans for the rock samples with filter cake before and after fracturing (Experiment 2). 
Figure 11 shows the NMR scans for the case of partial filter cake removal using a $20 \mathrm{wt} \%$ DTPA chelating agent at $200{ }^{\circ} \mathrm{F}$. The removal efficiency was $40 \%$, which means still $60 \%$ of the filter cake is covering the wall of the drilled hole. The NMR scan for the rock with the filter cake showed very similar behavior to that in the case of Figure 10 in which the filter cake completely plugged the connection between the hole (macropores) and the rest of the pore system. This plugging was confirmed by a zero-diffusion coupling between the hole and the rock, in which no communication between the two-pore systems, and the $\mathrm{H}^{+}$protons cannot diffuse between the two-pore systems. This happened due to the zero permeability of the filter cake that is formed at the wall of the hole. The NMR scan shows that after the partial removal of the filter cake, the connectivity between the hole (macropores) and the rest of the rock system is partially restored, and the diffusion coupling between the different pore systems is partially restored, compared to before the filter cake removal. The created fracture enhanced the connectivity between the hole and the rest of the pore systems, as indicated by the increase in the diffusion coupling intensity between macro-/mesopore and meso-/micropore systems. Mahmoud [53] introduced the concept of the interconnectivity between the different pore systems in the rock using the diffusion coupling from NMR scans. In this case, the interconnectivity number is the value of the intensity of the diffusion coupling between the macro-/mesopore system to that of the meso-/micropore system. In Figure 11, the three cases interconnectivity number (ICN) can be presented as follows:

1. Before treatment, in which the filter cake completely plugged the connection between the hole and the pore systems in the rock, ICN $=0 / 0.025=$ zero;

2. In the case of partial removal of the filter cake, $\mathrm{ICN}=0.02 / 0.03=0.67$;

3. After creating the fracture (with water) through the partially removed filter cake, $\mathrm{ICN}=0.045 / 0.65=0.70$.

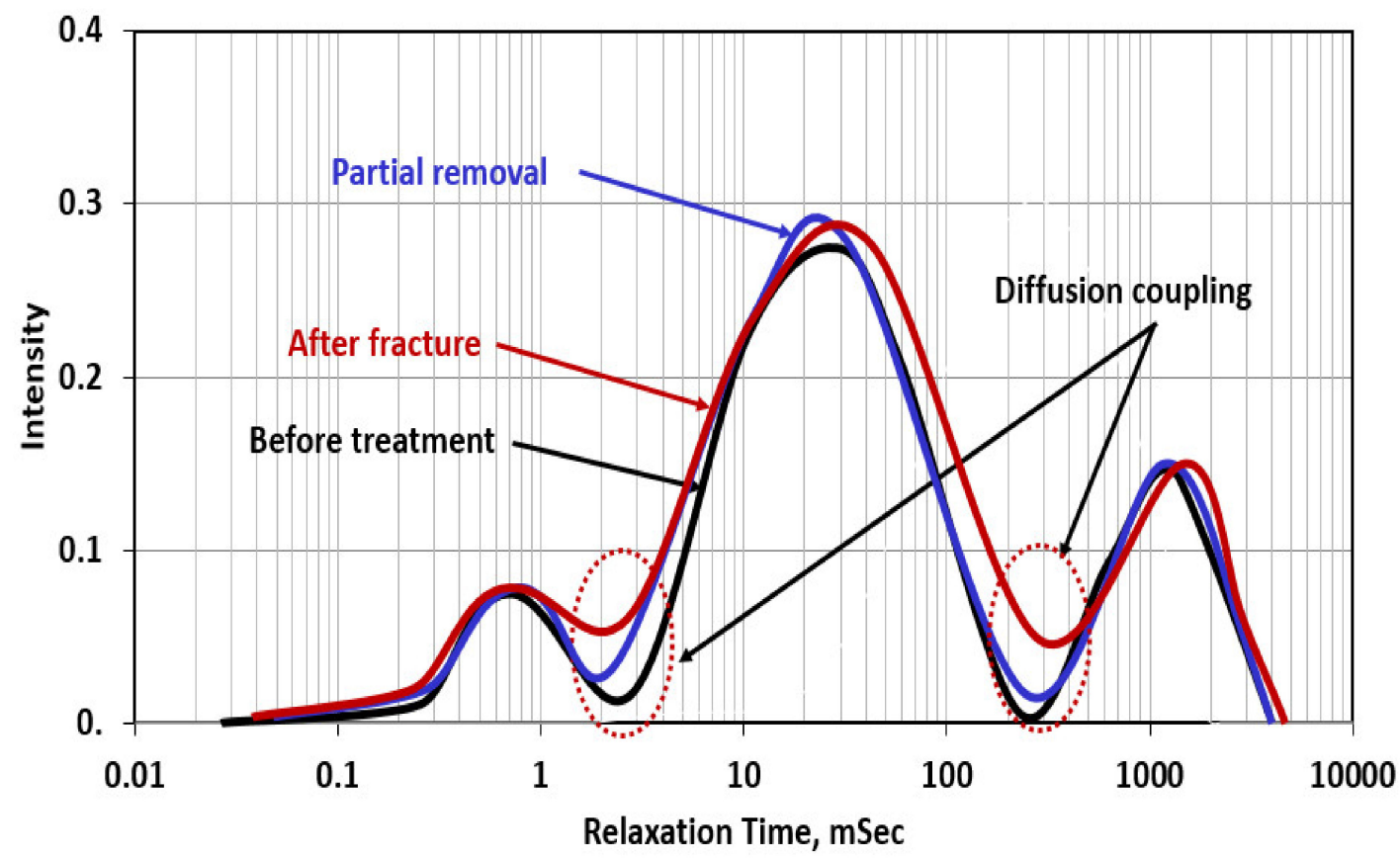

Figure 11. NMR scans for the rock samples with partial filter cake before and after fracturing (Experiment 3).

Figure 12 shows the NMR scans for the case of complete filter cake removal using $20 \mathrm{wt} \%$ DTPA chelating agent at $\mathrm{pH} 11+10 \mathrm{wt} \%$ GLDA at $\mathrm{pH} 11+9 \mathrm{wt} \% \mathrm{~K}_{2} \mathrm{CO}_{3}$ at $200{ }^{\circ} \mathrm{F}$ for $24 \mathrm{~h}$. In this case, the filter cake caused very similar damage to the previous cases and completely plugged the interconnectivity between the hole and pore system in the rock. The complete removal of the filter cake (removal efficiency more than $90 \%$ ) resulted in enhancement in the diffusion coupling between the different pore systems in the rock 
(macro/meso and meso/micro). The created fracture using water has further enhanced the connection and increased the intensity of the diffusion coupling. In applying the concept of the interconnectivity number in this case, the following are the results of ICN estimation for the three NMR scans:

1. Before treatment in which the filter cake completely plugged the connection and covered the wall of the hole, $\mathrm{ICN}=0 / 0.25$ = zero;

2. Complete removal of the filter cake: in this case, the remover fluid removed both the filter cake and the polymer; the used formulation consists of GLDA chelating agent that can break the polymer coat and DTPA + K2CO3 to remove the barite. In this case, the ICN =0.3/0.4 = 0.75;

3. After fracture (with water), the $\mathrm{ICN}=0.45 / 0.60=0.75$.

The creation of the fracture with water did not improve the ICN value after the complete removal of the filter cake, which indicates the inefficiency of using water to create a fracture in tight rocks.

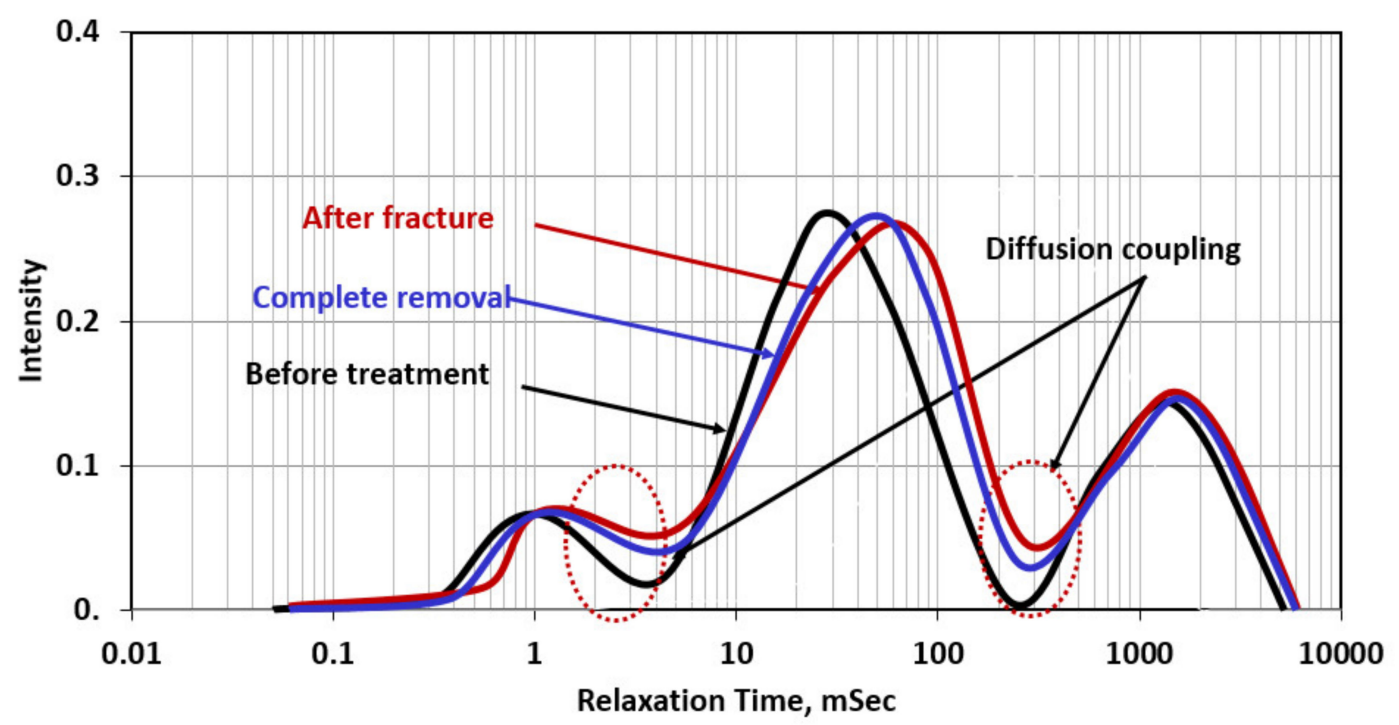

Figure 12. NMR scans for the rock samples with complete removal of the filter cake before and after fracturing (Experiment 4).

Figure 13 shows the NMR scans for the last case in which TCF combined with chelating agent and catalyst to remove the filter cake and create multiple fractures in the rock. The fluids used here are two thermochemical fluids (sodium nitrate + ammonium chloride); when reacting at the reservoir temperature, they will generate a very high-pressure pulse that will create major and microfractures. In addition, the reaction will generate a high temperature (an additional $100^{\circ} \mathrm{F}$ ), which will promote the reaction of the chelating agent and catalyst with the filter cake. The interconnectivity number calculations can be presented as follows:

1. Before treatment, in which the filter cake completely covered the hole, $\mathrm{ICN}=0$ / 0.02 = zero;

2. Complete removal + fracture; in this case, the filter cake was completely removed, and TCF created a fracture and microfractures around the hole, ICN $=0.075 / 0.08=0.94$. The interconnectivity number, in this case, was the highest among all cases presented in this study due to the creation of microfractures (as shown in Figure 8), in addition to the major fracture. In addition, the complete removal of the filter cake obtained from the thermochemical treatment enhanced the communication between the different pore systems in the rock. 


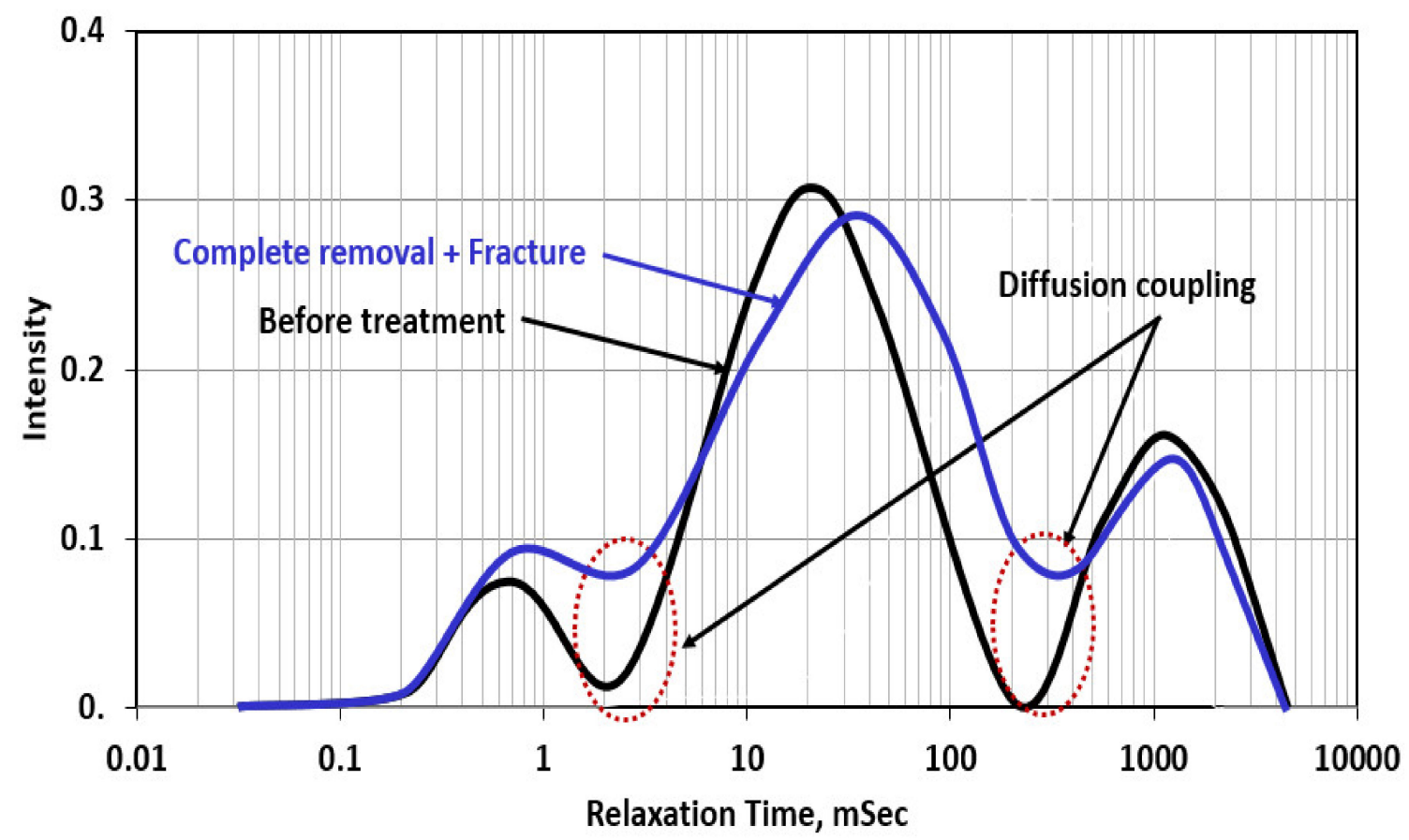

Figure 13. NMR scans for the rock samples with complete removal of the filter cake before and after fracturing (Experiment 5).

Figure 14 shows the effect of filter cake conditions on the interconnectivity number. There is a strong relationship between the filter cake removal efficiency and the ICN and the effect of the type of remover. The ICN indicates the degree of connectivity between the different pore systems in the rock. The initial conditions of the rock without filter cake showed an ICN of 0.77 , which shows good connectivity between the macro-/mesopores and meso-/micropores in the rock. The ICN was estimated for the samples after fracturing treatment with either water or TCF. Even fracturing could not restore the interpore connectivity due to the formation of the filter cake; the ICN value was 0.5 for the fractured rock with no filter cake removal. This elucidates the mandatory need for filter cake removal to restore the communication between the pore systems. The fractured rock after partial removal of the filter cake (removal efficiency $40 \%, 60 \%$ of the filter cake still exists) yielded an ICN of 0.67 , which also indicates that partial removal of the filter cake will not provide favorable conditions for the flow and will not restore the communication between the pores ad the fracture and this will impact the well's productivity. The complete removal of the filter cake (removal efficiency $90 \%, 10 \%$ of the filter cake still covering the wall of the hole) restored the pore connectivity after fracturing to almost the original value; the ICN, in this case, was 0.75 , compared to 0.77 in the case of the fractured rock without filter cake. The application of thermochemical fluid (TCF) in addition to the filter cake remover $\left(20 \mathrm{wt} \%\right.$ DTPA $+10 \mathrm{wt} \%$ GLDA at $\mathrm{pH} 11+9 \mathrm{wt} \% \mathrm{~K}_{2} \mathrm{CO}_{3}$ ) yielded the highest ICN value after fracturing. The ICN, in this case, was 0.94 , which is much higher, compared to all the reported cases, and higher compared to the original rocks without filter cake. This means that the addition of TCF enhanced the connectivity between the pore systems through the creation of the main fracture and microfractures around the whole. 


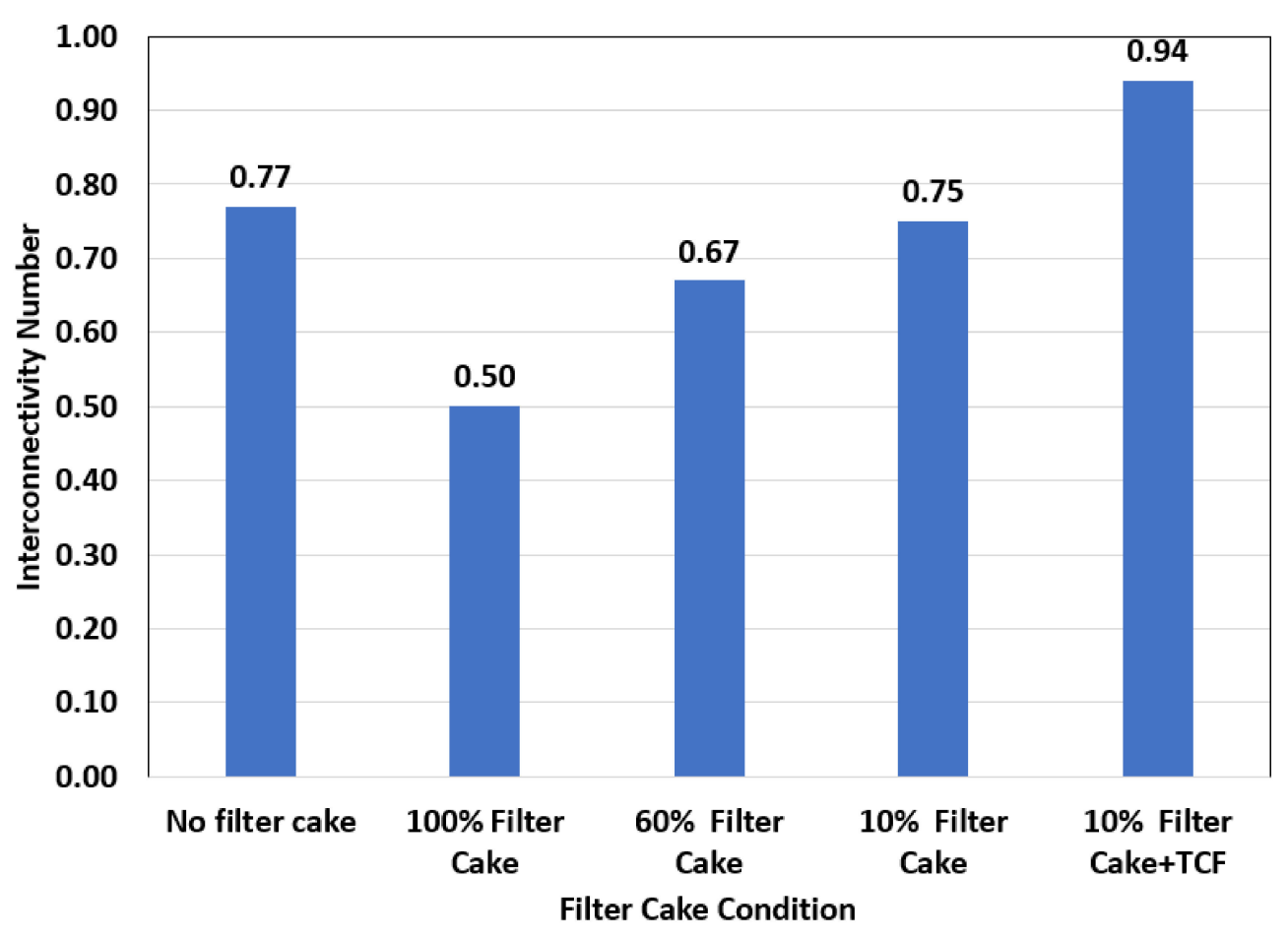

Figure 14. Relationship between filter cake condition and interconnectivity number (ICN).

Figure 15 shows the relationship between the breakdown pressure and the interconnectivity number after fracturing for the five cases reported previously. There is a strong relationship between the ICN and fracture pressure. Lower breakdown pressure resulted in a very high interconnectivity number, and higher breakdown pressure yielded a very low interconnectivity number. This means in tight rocks with damage due to filter cake, fracturing itself may not be sufficient to have good production from the well, and additional operations such as filter cake and damage removal may be required to enhance the production and enhance the connectivity between the created fracture and the pore system in the rocks. This should be considered carefully in different rocks, such as tight and unconventional rocks.

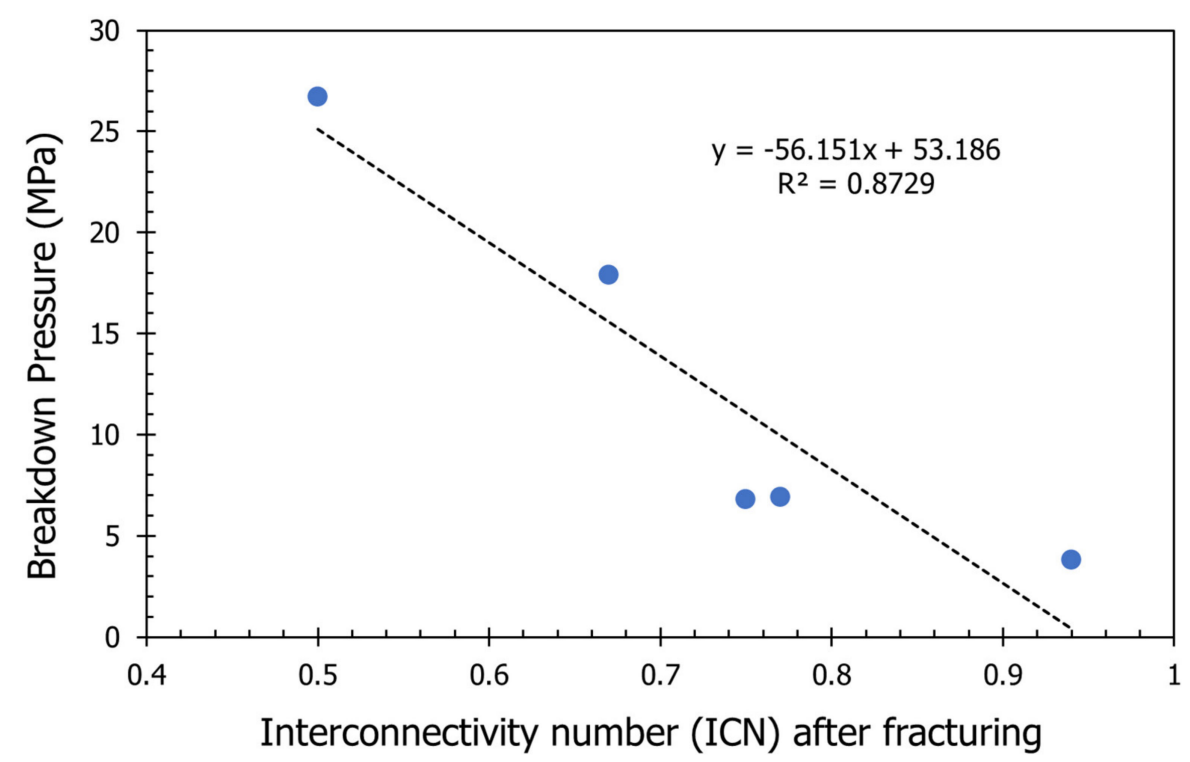

Figure 15. Relationship between breakdown pressure and interconnectivity number (ICN). 
The method proposed in this work can be used to evaluate the fracture treatment efficiency in creating and well-connected fractures to the pore system in the rock to have good communication between the fractures and the rocks and facilitate the production from tight reservoirs.

\section{Breakdown Pressure Modeling}

Experimental outcomes show that the filter cake's existence, which acts as a seal, increases the breakdown pressure of the formation. From a theoretical perspective, the filter cake prevents any communication between the wellbore and the formation. The partial filter cake might not prevent communication, but it reduces the rock permeability around the wellbore. In this section, a model is created to show the impact of filter cake on the breakdown pressure. The model also is used to show how removing filter cake can reduce the breakdown pressure. It integrates a flow model (to simulate fluid injection) with popular analytical solutions to estimate the breakdown pressure. The breakdown pressure of the formation in a vertical wellbore assuming no fluid penetration can be estimated using the classical Hubbert and Willis [54] (H-W) approach as follows:

$$
p_{b}=3 \sigma_{\text {hmin }}-\sigma_{\text {Hmax }}+T-p_{o}
$$

where $p_{b}$ is the breakdown pressure, $\sigma_{\text {hmin }}$ is the minimum horizontal stress, $\sigma_{\text {Hmax }}$ is the maximum horizontal stress, $p_{o}$ is the pore pressure, and $T$ is the formation tensile strength. The equation above can be used to predict the breakdown pressure assuming complete filter cake around the wellbore (no fluid penetration). For the cases where fluids penetrate the formation, the breakdown pressure declines with the increase in pore pressure. The breakdown pressure can be estimated using the Haimson and Fairhurst [55] (H-F) Equation as follows:

$$
p_{b}=\frac{3 \sigma_{\text {hmin }}-\sigma_{\text {Hmax }}+T-2 \eta p_{o}}{2(1-\eta)}
$$

where

$$
\eta=\frac{\alpha(1-2 v)}{2(1-v)} \quad 0 \leq \eta \leq 0.5
$$

and where $\alpha$ represents the Biot coefficient and $v$ is the Poisson ratio. Smith and Montgomery [56] stated that $\eta=0.25$ is suitable for field applications of breakdown prediction. Both H-W and H-F approaches assume that the breakdown will occur if the effective tangential stress is equal to the rock tensile strength. The equation above can be used to predict the breakdown pressure for no filter cake, partial filter cake, and complete removal of filter cake if the change in pore pressure is considered. The above equations do not consider the change in pore pressure as the fluid is injected. Detournay and Cheng [57] (D-C) investigated the impact of pressurizing rate on the breakdown pressure by providing the following analytical solution:

$$
p_{b}=\frac{3 \sigma_{h \min }-\sigma_{\operatorname{Hmax}}+T-2 p_{o}}{1+(1-2 \eta) h(\gamma)}+p_{o}
$$

where $h(\gamma)$ is a function that represents the pressurizing rate. The advantage of the D-C model is that it returns the $\mathrm{H}-\mathrm{W}$ model at a high pressurizing rate where no fluid is allowed to penetrate the formation. In this case, $h(\gamma)=0$, and hence, Equation (2) is obtained. It also returns Equation (3) under a slow pressurizing rate where fluid is allowed to penetrate the formation. In this case, $h(\gamma)=1$, and hence, Equation (3) is returned. Although the D-C model is incorporating the impact of pressurizing on the breakdown pressure, it is challenging to relate between the skin (i.e., reduction of permeability around the wellbore) and the pressurizing rate.

A flow model was incorporated in this study to estimate the increase in pore pressure as the fracturing fluid is injected. The skin factor or permeability reduction can be easily 
incorporated into the flow model. The mass conservation equation in porous media and Darcy's law are used to estimate the pressure profile during injection as follows:

$$
\begin{gathered}
\nabla \cdot(\rho \boldsymbol{u})=-\frac{\partial(\rho \phi)}{\partial t} \\
\boldsymbol{u}=-\frac{\boldsymbol{k}}{\mu} \cdot \nabla p
\end{gathered}
$$

where $\rho$ is the fluid density, $\boldsymbol{u}$ is the velocity vector, $\phi$ is the rock porosity, $t$ is time, $\boldsymbol{k}$ is the permeability tensor, $\mu$ is the viscosity, and $p$ is the pressure. The above equations were solved assuming no flow outer boundary conditions and constant flow at the wellbore location. The pore pressure is assumed to be equal to the average pressure surrounding the wellbore, $\bar{p}$, which is calculated as

$$
p_{o}=\bar{p}=\frac{\int p d V}{\int d V}
$$

The model, which was coded using MATLAB, starts by solving the flow model to obtain both the wellbore pressure $p_{w}$ and the pore pressure $p_{0}$. The simulator stops when the breakdown occurs by satisfying the following criterion:

$$
p_{w}=p_{b}
$$

The permeability around the wellbore (skin) is altered in the flow simulator to simulate different filter cake conditions. Equation (2) is used to estimate $p_{b}$ for complete filter cake, while Equation (3) is used for the other scenarios.

\section{Modeling Results}

First, the classical H-W and H-F models can show the impact of complete filter cake on the breakdown pressure. As mentioned, the $\mathrm{H}-\mathrm{W}$ model assumes no fluid penetration, which is suitable for predicting the breakdown pressure when a filter cake completely seals the formation. The H-F model can be used to estimate the breakdown pressure assuming

\begin{tabular}{|c|c|c|}
\hline Input & SI Unit & Field Unit \\
\hline$k$ & $9.869 \times 10^{-15} \mathrm{~m}^{2}$ & $10 \mathrm{mD}$ \\
\hline$\phi$ & \multicolumn{2}{|c|}{0.2} \\
\hline Injection rate, $q$ & $0.053 \mathrm{~m}^{3} / \mathrm{s}$ & $2 \mathrm{bpm}$ \\
\hline Initial pressure, $p_{i}$ & $29.85 \mathrm{MPa}$ & 4330 psi \\
\hline$\mu$ & $1 \mathrm{mPa} . \mathrm{s}$ & $1 \mathrm{cp}$ \\
\hline Total compressibility, $c_{t}$ & $1.45 \times 10^{-4} 1 / \mathrm{MPa}$ & $1 \times 10^{-\frac{1}{6}} 1 / \mathrm{psi}$ \\
\hline$\sigma_{h \min }$ & $41.4 \mathrm{MPa}$ & 6000 psi \\
\hline$\sigma_{\text {Hmax }}$ & $41.4 \mathrm{MPa}$ & 6000 psi \\
\hline$T$ & 8.3 $\mathrm{MPa}$ & 1200 psi \\
\hline$\eta$ & \multicolumn{2}{|c|}{0.25} \\
\hline
\end{tabular}
no filter cake. Table 5 shows the input parameter to predict the breakdown pressure using the model above.

Table 5. Input parameters for the breakdown prediction model.

Figure 16 shows the impact of filter cake on the breakdown pressure at different pore pressures representing different reservoir depths. It could be observed that the filter cake existence increases the breakdown pressure significantly, especially at low pore pressures. We used, in these simulations, constant $\eta$ value; nevertheless, it might change with depth due to the change in Poisson ratio and Biot's coefficient. 


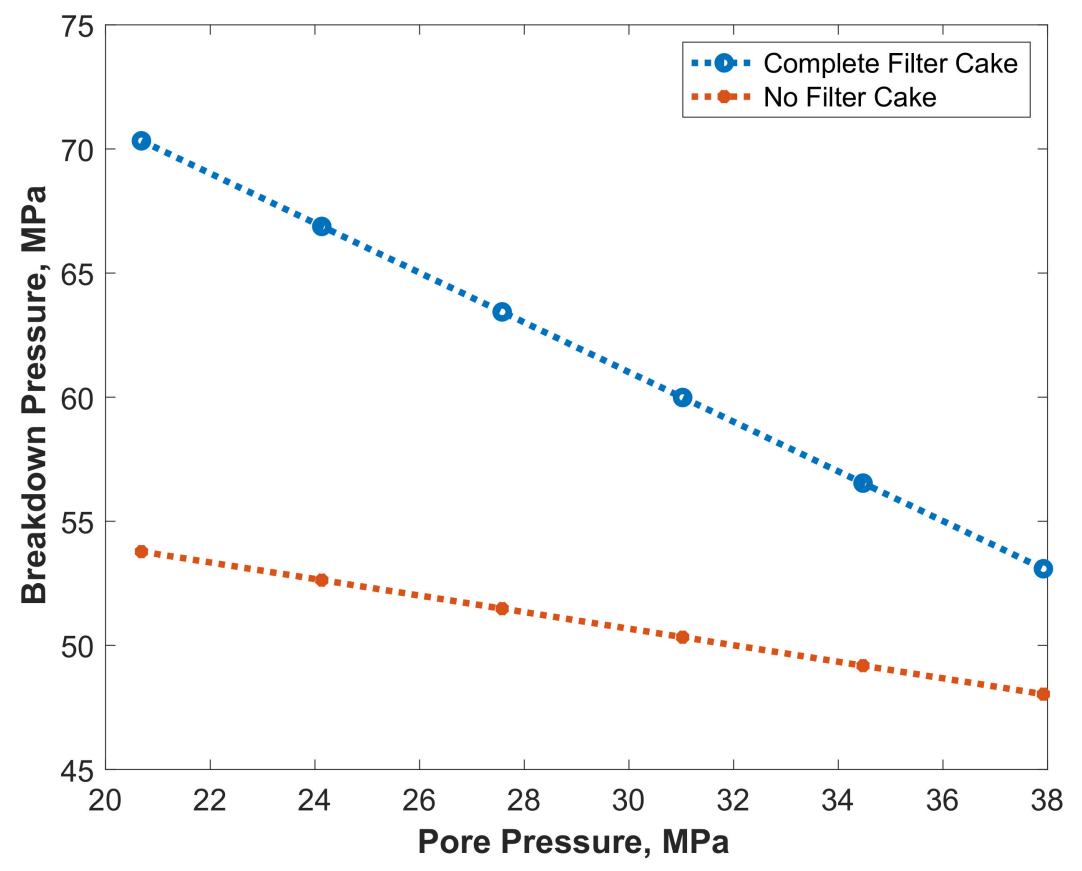

Figure 16. Impact of pore pressure on the breakdown pressure with and without filter cake.

Using the coupled numerical flow and analytical breakdown pressure models, the breakdown pressure was predicted for partial filter cake and complete filter cake removal cases. For the partial filter cake case, the permeability around the wellbore was assumed to be reduced by $50 \%$, compared to the original formation permeability. On the other hand, the permeability around the wellbore was assumed to increase to Darcy's range (1 Darcy) due to TCF treatment. Additionally, due to the microcrack created by the TC, the formation tensile strength is reduced significantly (approaches zero). It is assumed that the damaged and stimulated zones are within $0.304 \mathrm{~m}$ from the wellbore. Figure 17 shows the outcomes of the flow model illustrating the pressurizing rate. Figure 17a shows that the pressure increases significantly in the wellbore due to the existence of filter cake. In contrast, Figure $17 \mathrm{~b}$ shows that the pressure increase was lower in the wellbore, and the pore pressure surrounding the wellbore increased noticeably. According to Equation (3), high pore pressure would result in a lower breakdown pressure.

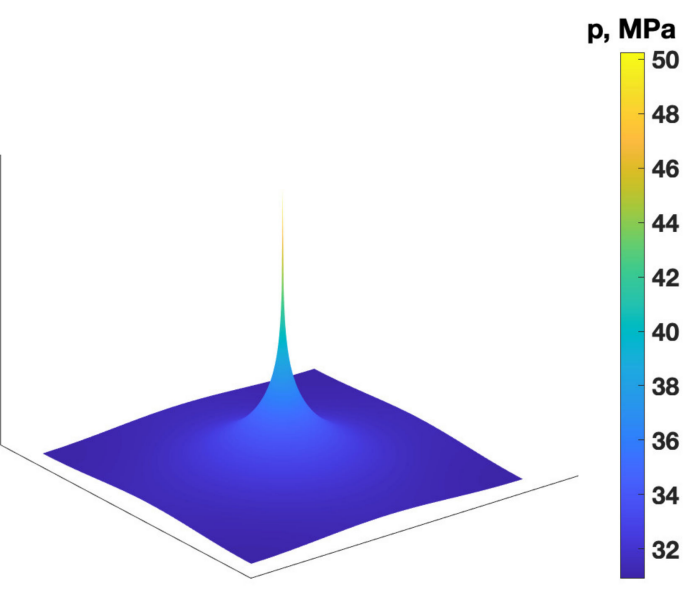

(a) Partial Filter Cake

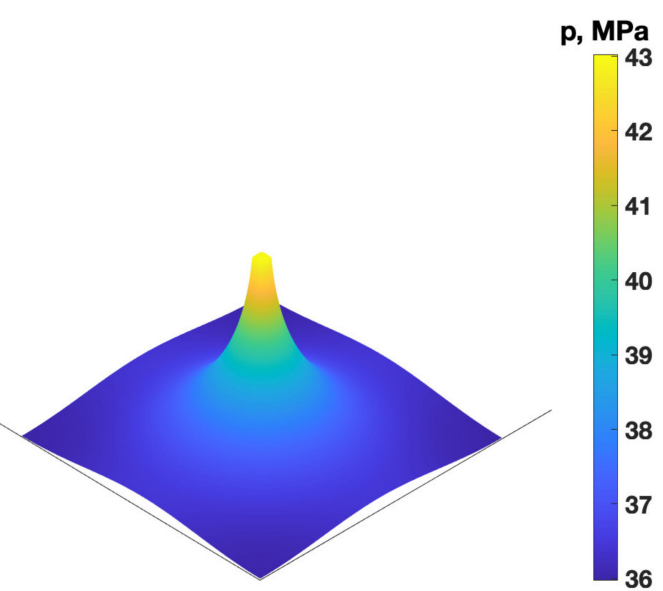

(b) Complete Filter Cake Removal

Figure 17. Pressure profile around the wellbore assuming (a) partial filter cake and (b) complete filter cake removal using TCF. 
Figure 18 shows that the formation breakdown occurs when the breakdown pressure is equal to the wellbore pressure. The breakdown pressure is not constant, and it changes with the increase in pore pressure, which increases with injection time. Additionally, the wellbore pressure increases with the injection time until reaching the breakdown pressure. The model shows that the breakdown pressure due to the existence of partial filter cake was $50 \mathrm{MPa}$. The TCF treatment reduced the breakdown pressure to $43 \mathrm{MPa}$ due to increased pore pressure and reduced rock tensile strength. Obviously, it takes longer to achieve formation breakdown, assuming the same injection rate, after TCF treatments due to the high injectivity created. This allows a higher injection rate of fracturing fluids without creating high-pressure values at the surface. Fundamentally, increasing the injection rate should reduce the time at which formation breakdown occurs.

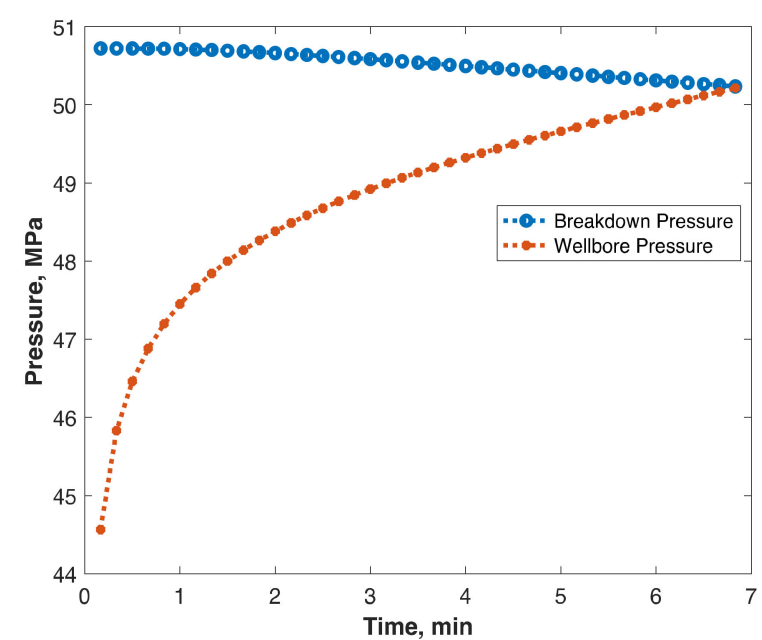

(a) Partial Filter Cake

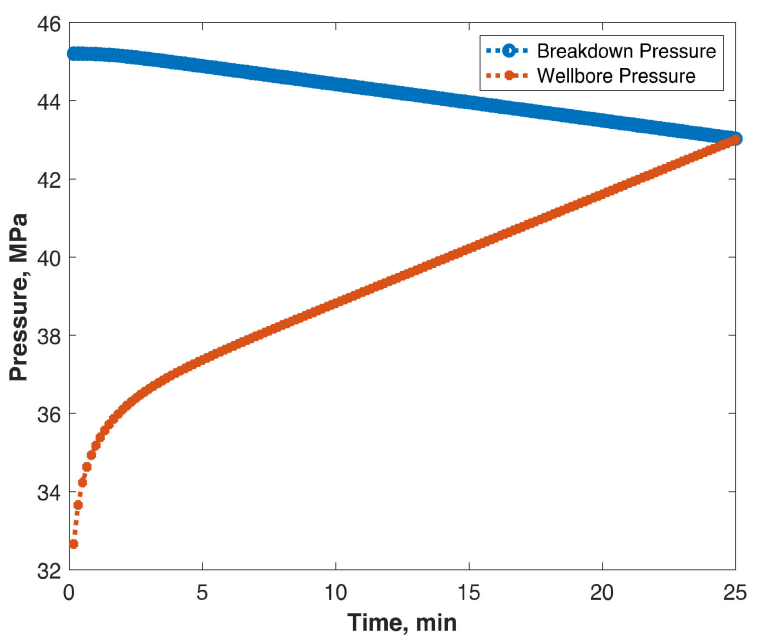

(b) Complete Filter Cake Removal

Figure 18. Prediction of the breakdown pressure using the integrated model assuming (a) partial filter cake and (b) complete filter cake removal using TCF.

\section{Conclusions}

This study presented a novel approach to reduce the required breakdown pressure of the formation containing the water-based drilling fluid filter cake. Based on the experimental results, conducted analysis, and the discussion presented in this study, the following conclusions can be drawn:

1. Filter cake increased the breakdown pressure more than four times due to the wellbore strengthening effect. Breakdown pressure was increased from 6.9 MPa (case without filter cake) to $26.7 \mathrm{MPa}$ (case with complete filter cake).

2. Partial removal of the filter cake with $20 \mathrm{wt} \%$ DTPA resulted in $40 \%$ removal of the filter cake. This resulted in a 33\% reduction in breakdown pressure from $26.7 \mathrm{MPa}$ (case with complete filter cake) to $17.9 \mathrm{MPa}$ (case with partial filter cake).

3. The chelating agents such as $20 \mathrm{wt} \%$ DTPA, $10 \mathrm{wt} \%$ GLDA, and $9 \mathrm{wt} \% \mathrm{~K}_{2} \mathrm{CO}_{3}$ resulted in complete dissolution of the filter cake, and the required breakdown pressure of the rock was similar to the one without filter cake.

4. Using thermochemical treatment combined with DTPA to remove the filter cake resulted in a further decrease of the breakdown pressure due to the complete removal of the filter cake in addition to the creation of microfractures.

5. The compressive strength of the samples after fracturing experiments was aligned with the breakdown pressure.

6. The diffusion coupling through NMR scans confirmed the higher interconnectivity between different pore systems after the combined thermochemical and chelating agent treatment. 
7. A strong relationship between the interconnectivity number $(\mathrm{ICN})$ and fracture pressure was observed; lower breakdown pressure resulted in a very high interconnectivity number, and higher breakdown pressure yielded a very low interconnectivity number.

8. A model was created to predict the breakdown pressure at a field scale. It shows that filter cake removal in terms of TCF treatment can reduce the breakdown pressure significantly.

Author Contributions: Conceptualization, M.M.; methodology, Z.T., M.M., M.S.K.; software, M.S.A.; formal analysis, Z.T., M.S.A., M.M., O.A.; data curation, Z.T., M.S.A., M.M.; writing-original draft preparation, Z.T., M.S.A., M.M.; resources, M.S.K., A.A.-N. All authors have read and agreed to the published version of the manuscript.

Funding: This research received no external funding.

Institutional Review Board Statement: Not applicable.

Informed Consent Statement: Not applicable.

Data Availability Statement: Not applicable.

Acknowledgments: The authors would like to thank CPG for the support.

Conflicts of Interest: The authors declare no conflict of interest.

Sample Availability: Samples of the compounds are not available from the authors.

\section{References}

1. Yang, M.; Li, M.C.; Wu, Q.; Growcock, F.B.; Chen, Y. Experimental study of the impact of filter cakes on the evaluation of LCMs for improved lost circulation preventive treatments. J. Pet. Sci. Eng. 2020, 191, 107152. [CrossRef]

2. Min, F.; Du, J.; Zhang, N.; Chen, X.; Lv, H.; Liu, L.; Yu, C. Experimental study on property change of slurry and filter cake of slurry shield under seawater intrusion. Tunn. Undergr. Space Technol. 2019, 88, 290-299. [CrossRef]

3. Siddig, O.; Mahmoud, A.A.; Elkatatny, S. A review of different approaches for water-based drilling fluid filter cake removal. J. Pet. Sci. Eng. 2020, 192, 107346. [CrossRef]

4. Zhang, Y.; He, J.; Li, X.; Lin, C. Experimental study on the supercritical $\mathrm{CO}_{2}$ fracturing of shale considering anisotropic effects. J. Pet. Sci. Eng. 2019, 173, 932-940. [CrossRef]

5. Detournay, E.; Carbonell, R. Fracture-Mechanics Analysis of the Breakdown Process in Minifracture or Leakoff Test. SPE Prod. Facil. 1997, 12, 195-199. [CrossRef]

6. Warpinski, N.R.; Wolhart, S.L.; Wright, C.A. Analysis and prediction of microseismicity induced by hydraulic fracturing. SPE J. 2004, 9, 24-33. [CrossRef]

7. Patel, S.M.; Sondergeld, C.H.; Rai, C.S. Laboratory studies of hydraulic fracturing by cyclic injection. Int. J. Rock Mech. Min. Sci. 2017, 95, 8-15. [CrossRef]

8. Song, X.; Guo, Y.; Zhang, J.; Sun, N.; Shen, G.; Chang, X.; Yu, W.; Tang, Z.; Chen, W.; Wei, W.; et al. Fracturing with Carbon Dioxide: From Microscopic Mechanism to Reservoir Application. Joule 2019, 3, 1913-1926. [CrossRef]

9. Al-muntasheri, G.A.; Advanced, E.; Aramco, S. Nanoparticle-Enhanced Hydraulic-Fracturing Fluids: A Review. SPE Prod. Oper. 2016, 32, 186-195. [CrossRef]

10. Warpinski, N.R.; Mayerhofer, M.J.; Vincent, M.C.; Cipolla, C.L.; Lolon, E.R. Stimulating unconventional reservoirs: Maximizing network growth while optimizing fracture conductivity. J. Can. Pet. Technol. 2009, 48, 39-51. [CrossRef]

11. Rogala, A.; Ksiezniak, K.; Krzysiek, J.; Hupka, J. Carbon dioxide sequestration during shale gas recovery. Physicochem. Probl. Miner. Process. 2014. [CrossRef]

12. Chu, Z.; Dreiss, C.A.; Feng, Y. Smart wormlike micelles. Chem. Soc. Rev. 2013, 42, 7174-7203. [CrossRef]

13. Lee, K.S.; Kim, T.H. Integrative Understanding of Shale Gas Reservoirs; Springer International Publishing: Cham, Switzerland, 2016; ISBN 978-3-319-29295-3.

14. Gomaa, A.M.; Qu, Q.; Nelson, S.; Maharidge, R. New insights into shale fracturing treatment design. In Proceedings of the Society of Petroleum Engineers-European Unconventional Resources Conference and Exhibition 2014: Unlocking European Potential, Vienna, Austria, 25-27 February 2014; Society of Petroleum Engineers: Richardson, TX, USA, 2014; Volume 2, pp. 658-672.

15. Wu, X.; Xia, J.; Guan, B.; Yan, X.; Zou, L.; Liu, P.; Yang, L.; Hong, S.; Hu, S. Water availability assessment of shale gas production in the Weiyuan play, China. Sustainability 2019, 11, 940. [CrossRef]

16. Nasr-El-Din, H.A.; Al-Mutairi, S.H.; Al-Hajji, H.H.; Lynn, J.D. Evaluation of a New Barite Dissolver: Lab Studies. In Proceedings of the SPE International Formation Damage Control Symposium Proceedings, Lafayette, LA, USA, 18-20 February 2004; Society of Petroleum Engineers: Richardson, TX, USA, 2004. 
17. Nasr-El-Din, H.A.; Al-Otaibi, M.B.; Al-Qahtani, A.A.; Al-Fuwaires, O.A. Filter-cake cleanup in MRC wells using enzyme/surfactant solutions. In Proceedings of the SPE International Symposium and Exhibition on Formation Damage Control, Lafayette, LA, USA, 15-17 February 2006; pp. 667-680.

18. Xiao, J.; Nasr-Ei-din, H.A.; Al-Bagoury, M. Evaluation of micronized llmenite as a weighting material in oil-based drilling fluids for HPHT applications. In Proceedings of the SPE-European Formation Damage Conference Proceedings, EFDC, Society of Petroleum Engineers, Richardson, TX, USA, 5-7 June 2013; Volume 2, pp. 1017-1030.

19. Jiao, D.; Sharma, M.M. Formation Damage Due to Static and Dynamic Filtration of Water-Based Muds. In Proceedings of the SPE Formation Damage Control Symposium, Lafayette, LA, USA, 26-27 February 1992; Society of Petroleum Engineers: Richardson, TX, USA, 1992.

20. Hajiabadi, S.H.; Aghaei, H.; Kalateh-Aghamohammadi, M.; Sanati, A.; Kazemi-Beydokhti, A.; Esmaeilzadeh, F. A comprehensive empirical, analytical and tomographic investigation on rheology and formation damage behavior of a novel nano-modified invert emulsion drilling fluid. J. Pet. Sci. Eng. 2019, 181, 106257. [CrossRef]

21. Ba Geri, B.S.; Al-Mutairi, S.H.; Mahmoud, M.A. Different techniques for characterizing the filter cake. In Proceedings of the the SPE Unconventional Gas Conference and Exhibition, Muscat, Oman, 28-30 January 2013; pp. 104-116.

22. Bageri, B.S.; Mahmoud, M.; Abdulraheem, A.; Al-Mutairi, S.H.; Elkatatny, S.M.; Shawabkeh, R.A. Single stage filter cake removal of barite weighted water based drilling fluid. J. Pet. Sci. Eng. 2017, 149, 476-484. [CrossRef]

23. Mahmoud, M. Well Clean-Up Using a Combined Thermochemical/Chelating Agent Fluids. J. Energy Resour. Technol. 2019, 141 [CrossRef]

24. Mahmoud, M.A.N.E.D.; Elkatatny, S. Removal of barite-scale and barite-weighted water- Or oil-based-drilling-fluid residue in a single stage. SPE Drill. Complet. 2019, 34, 16-26. [CrossRef]

25. Mahadi, K.A.; Nizam, M.M.; Jadid, M.B.; Ogbonna, C.; Hashim, S.; Chen, Y.C. Use of acid precursor as alternative to acid treatment to drill-in fluid filter cake removal: FN case study. In Proceedings of the Society of Petroleum Engineers-International Petroleum Technology Conference 2014, IPTC 2014-Innovation and Collaboration: Keys to Affordable Energy, Kuala Lumpur, Malaysia, 10-12 December 2014; Volume 1, pp. 98-111.

26. Howard, S.K. Formate brines for drilling and completion: State of the art. In Proceedings of the the SPE Annual Technical Conference and Exhibition, Dallas, TX, USA, 22-25 October 1995; pp. 31-39.

27. Al-Anzi, N.A.; Haider, B.Y.A.; Gohain, A.K.; Hussain, I.; Davidson, E.; Macmillan, B.H. Carefully designed water-based drill-in fluid and filter cake removal system improves reservoir producibility and reduce well completion costs. In Proceedings of the 8th European Formation Damage Conference, Scheveningen, The Netherlands, 27-29 May 2009.

28. Zubail, M.A.; Al-Kuait, A.M.; Al-Yateem, K.S.; El Bialy, M.; Maghrabi, S.; Olivares, T.; Ezell, R.G. Improved Producibility after Delayed Filter Cake Breaker Treatment in the Safaniya Offshore Field in Saudi Arabia. In Proceedings of the SPE Kuwait International Petroleum Conference and Exhibition, Kuwait City, Kuwait, 10-12 December 2012.

29. Al-Otaibi, M.A.; BinMoqbil, K.H.; Al-Rabba, A.S.; Abitrabi, A.N. Single-stage chemical treatment for oil-based mudcake cleanup: Field case and laboratory studies. In Proceedings of the SPE International Symposium and Exhibition on Formation Damage Control, Lafayette, LA, USA, 10-12 February 2010.

30. Quintero, L.; Jones, T.A.; Pietrangeli, G. Phase boundaries of microemulsion systems help to increase productivity. In Proceedings of the Society of Petroleum Engineers-9th European Formation Damage Conference, Noordwijk, The Netherlands, 7-10 June 2011; Society of Petroleum Engineers: Richardson, TX, USA, 2011; Volume 2, pp. 1275-1284.

31. Brege, J.; El Sherbeny, W.; Quintero, L.; Jones, T. Using microemulsion technology to remove oil-based mud in wellbore displacement and remediation applications. In Proceedings of the North Africa Technical Conference and Exhibition, Cairo, Egypt, 20-22 February 2012; SPE: Richardson, TX, USA, 2012.

32. Addagalla, A.K.; Kosandar, B.A.; Lawal, I.G.; Jadhav, P.B.; Imran, A.; Al Saqer, Q.R.; El Sherbeny, W.; Ansari, A.; Pino, R.; GadAlla, A.E.; et al. Overcoming OBM filter cake damage using micro-emulsion remediation technology across a high-temperature formation. In Proceedings of the SPE International Conference and Exhibition on Formation Damage Control, Lafayette, Louisiana, USA, 24-26 February 2016; SPE: Richardson, TX, USA, 2016.

33. Tan, Y.; Chen, H.; Wang, Z.; Xue, C.; He, R. Performances of cement mortar incorporating superabsorbent polymer (SAP) using different dosing methods. Materials 2019, 12, 1619. [CrossRef]

34. Tan, Y.; Gu, Q.; Ning, J.; Liu, X.; Jia, Z.; Huang, D. Uniaxial compression behavior of cement mortar and its damage-constitutive model based on energy theory. Materials 2019, 12, 1309. [CrossRef]

35. Yun, H.D.; Lee, J.W.; Jang, Y.I.; Jang, S.J.; Choi, W. Microstructure and mechanical properties of cement mortar containing phase change materials. Appl. Sci. 2019, 9, 943. [CrossRef]

36. Dong, B.; Qiu, Q.; Xiang, J.; Huang, C.; Xing, F.; Han, N. Study on the carbonation behavior of cement mortar by electrochemical impedance spectroscopy. Materials 2014, 7, 218-231. [CrossRef]

37. Yim, H.J.; Kim, J.H. Physical characterization of cementitious materials on casting and placing process. Materials 2014, 7 , 3049-3064. [CrossRef]

38. Wang, W.; Liu, X.; Guo, L.; Duan, P. Evaluation of properties and microstructure of cement paste blended with metakaolin subjected to high temperatures. Materials 2019, 16, 941. [CrossRef] [PubMed]

39. Nguyen, D.A.; Iwaniw, M.A.; Fogler, H.S. Kinetics and mechanism of the reaction between ammonium and nitrite ions: Experimental and theoretical studies. Chem. Eng. Sci. 2003, 58, 4351-4362. [CrossRef] 
40. Al-Nakhli, A.; Tariq, Z.; Mahmoud, M.; Abdulraheem, A.; Al-Shehri, D. A novel thermochemical fracturing approach to reduce fracturing pressure of high strength rocks. In Proceedings of the Abu Dhabi International Petroleum Exhibition E Conference, Abu Dhabi, United Arab Emirates, 11-14 November 2019; Society of Petroleum Engineers: Richardson, TX, USA, 2019.

41. Al-Nakhli, A.R.; Tariq, Z.; Mahmoud, M.; Abdulraheem, A. A state-of-the-art technology to reduce fracturing pressure in tight gas formations using thermochemical pulse. In Proceedings of the Unconventional Resources Technology Conference, Austin, TX, USA, 20-22 July 2020.

42. Rocha, N.O.; Khalil, C.N.; Leite, L.F.; Goja, A.M. Thermochemical Process To Remove Sludge From Storage Tanks. SPE Proj. Facil. Constr. 2009, 4, 97-102. [CrossRef]

43. Alade, O.S.; Mahmoud, M.; Hassan, A.; Al-Shehri, D.; Al-Nakhli, A.; Bataweel, M. Evaluation of Kinetics and Energetics of Thermochemical Fluids for Enhanced Recovery of Heavy Oil and Liquid Condensate. Energy Fuels 2019, 33, 5538-5543. [CrossRef]

44. Tariq, Z.; Mahmoud, M.A.; Abdulraheem, A.; Al-Nakhli, A.; Bataweel, M. An experimental study to reduce the fracture pressure of high strength rocks using a novel thermochemical fracturing approach. Geofluids 2019, 2019, 1-16. [CrossRef]

45. Tariq, Z.; Mahmoud, M.; Abdulraheem, A.; Al-Nakhli, A.; BaTaweel, M. An experimental study to reduce the breakdown pressure of the unconventional carbonate rock by cyclic injection of thermochemical fluids. J. Pet. Sci. Eng. 2020, 187, 106859. [CrossRef]

46. Tariq, Z.; Mahmoud, M.; Alade, O.; Abdulraheem, A.; Mustafa, A.; Mokheimer, E.M.A.; Al-Jawad, M.; Al-Nakhli, A. Productivity Enhancement in Multilayered Unconventional Rocks Using Thermochemicals. J. Energy Resour. Technol. 2021, $143,033001$. [CrossRef]

47. Mustafa, A.; Mahmoud, M.; Abdulraheem, A.; Tariq, Z.; Al-Nakhli, A. Improvement of petrophysical properties of tight sandstone and limestone reservoirs using thermochemical fluids. Petrophysics 2020, 61, 363-382. [CrossRef]

48. Wang, F.; Chen, H.; Alzobaidi, S.; Li, Z. Application and Mechanisms of Self-Generated Heat Foam for Enhanced Oil Recovery. Energy Fuels 2018, 32, 9093-9105. [CrossRef]

49. Ba Alawi, M.; Hassan, A.; Aljawad, M.S.; Kamal, M.S.; Mahmoud, M.; Al-Nakhli, A. A Novel Approach to Improve Acid Diversion in Carbonate Rocks Using Thermochemical Fluids: Experimental and Numerical Study. Molecules 2020, $25,2976$. [CrossRef] [PubMed]

50. Aljawad, M.S.; Mahmoud, M.; Abu-Khamsin, S.A. Mass and Heat Transfer of Thermochemical Fluids in a Fractured Porous Medium. Molecules 2020, 25, 4179. [CrossRef] [PubMed]

51. Barri, A.; Mahmoud, M.; Elkatatny, S. Evaluation of Rock Mechanical Properties Alteration During Matrix Stimulation With Chelating Agents. J. Energy Resour. Technol. 2016, 138, 032907. [CrossRef]

52. Tariq, Z.; Aljawad, M.S.; Hassan, A.; Mahmoud, M.; Al-Ramadhan, A. Chelating Agents as Acid-Fracturing Fluids: Experimental and Modeling Studies. Energy Fuels 2021, 35, 2602-2618. [CrossRef]

53. Mahmoud, M. Determination of the optimum wormholing conditions in carbonate acidizing using NMR. J. Pet. Sci. Eng. 2017, 159, 952-969. [CrossRef]

54. Hubbert, M.K.; Willis, D.G. Mechanics Of Hydraulic Fracturing. Trans. AIME 1957, 210, 153-168. [CrossRef]

55. Haimson, B.; Fairhurst, C. Hydraulic fracturing in porous-permeable materials. J. Pet. Technol. 1969, 21, 811-817. [CrossRef]

56. Smith, M.B.; Montgomery, C.T. Hydraulic Fracturing; CRC Press: Boca Raton, FL, USA, 2015; ISBN 9781466566927.

57. Detournay, E.; Cheng, A. Influence of pressurization rate on the magnitude of the breakdown pressure. In Proceedings of the 33rd U.S. Symposium on Rock Mechanics (USRMS), Santa Fe, NM, USA, 3-5 June 1992; Volume 30, pp. $325-333$. 